
العدد السادس عشر لسنة ه 1 •
مجلة البحث العلمى فى التربية

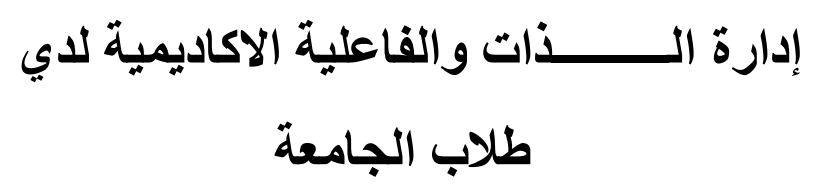

د/نجوي السيد إمام

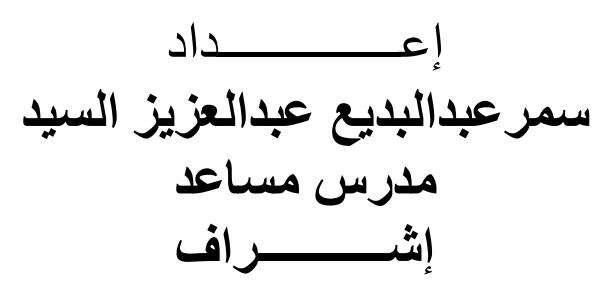

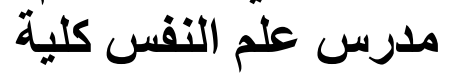

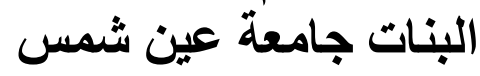

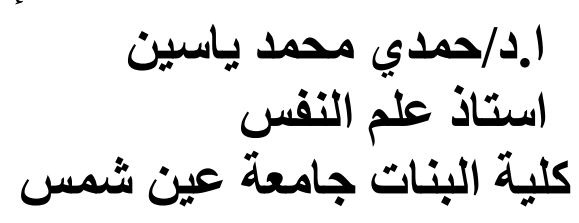

r. 10 
إن مهار ات إدارة الذات لاى الفرد تعد أساساً مهماً لتحديد مستوى دافعيته، ومستوى صحته الإنهي النفسية،

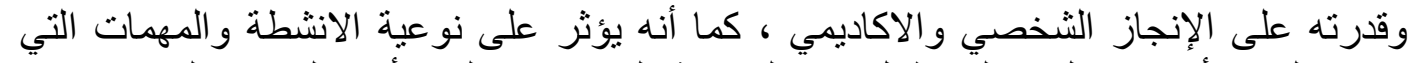

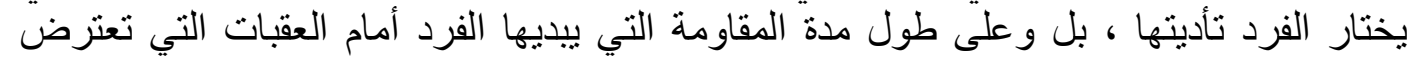

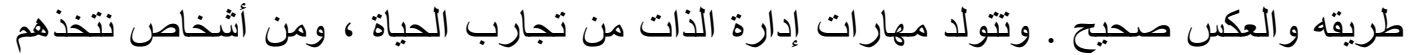
قدوة لنا.

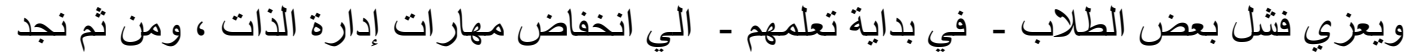

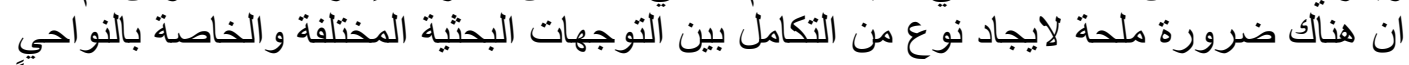

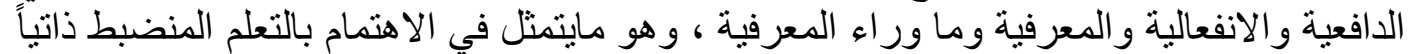
( الدنظم ذاتياً ) الذي يتيح الفرصة لتعليم الطلاب مدي الحياة ، فضيلاً عن تفوقهم في التحصيل التيطيل

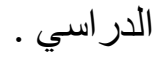

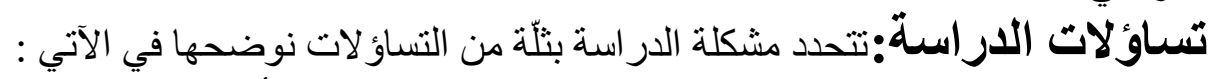
1 ـ هل تختلف متغيرات الدراسة النفسية ( إدارة الذات ـ الفاعلية الأكاديمية ) لدي عينة الدارية الأنية

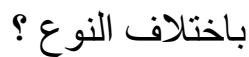

2- هل يمكن التنبؤ بإدارة الذات من خلال الفاعلية الاكاديمية لدي طلاب الجامعة ؟

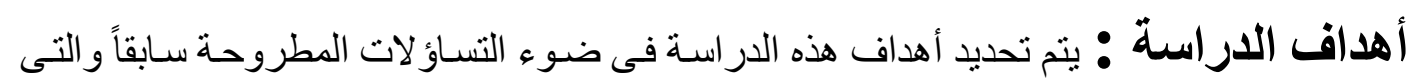

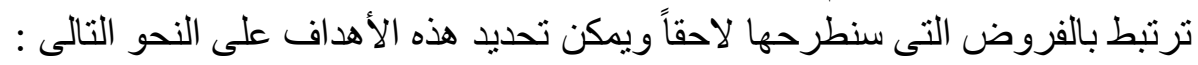

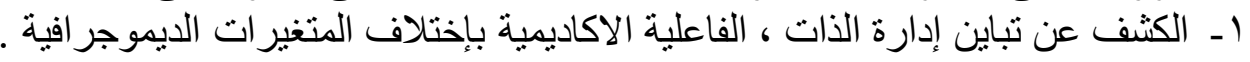

r- إمكانية التنبؤ بإدارة الذات من خلال الفاعلية الأكاديمية لدي طلاب الجامعة.

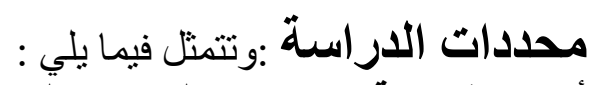

أدوات الاراسة : اعتمدت الدراسة علي الادوات الإدات التشخيصية التالية :مقياس ادارة الذات ، مقياس

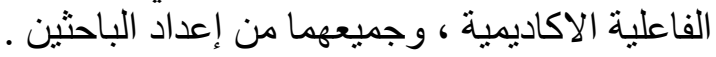

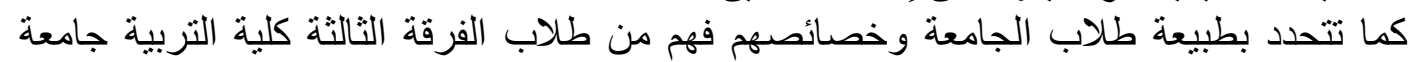

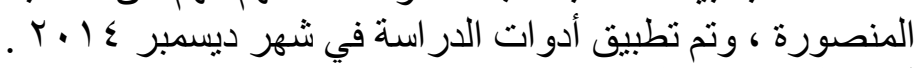

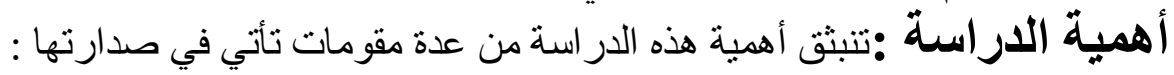

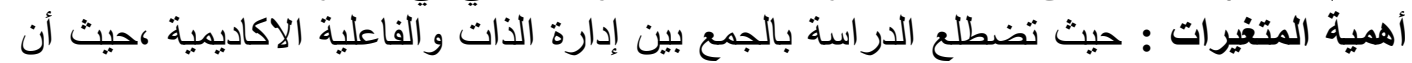

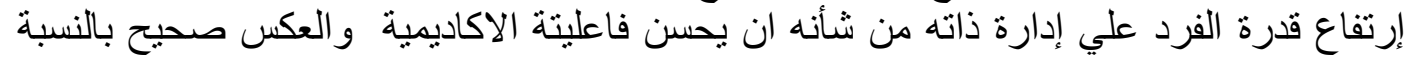

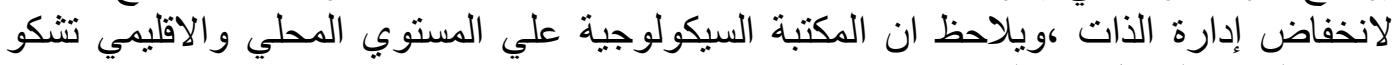

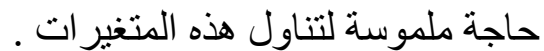
فضلاً عن الأهمية السيكومترية : و التي تمثلت في بناء وتلفيلة وتفيل (مقياس إدارة الذات ومقياس

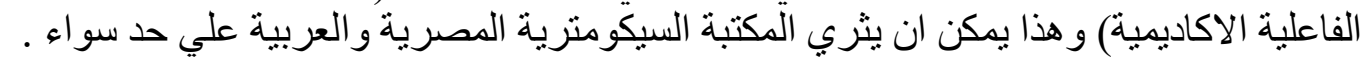

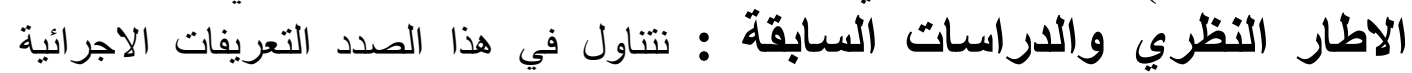

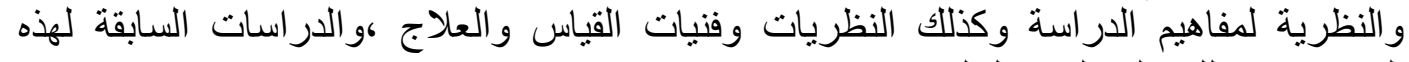

\section{Self Management}

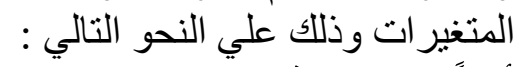

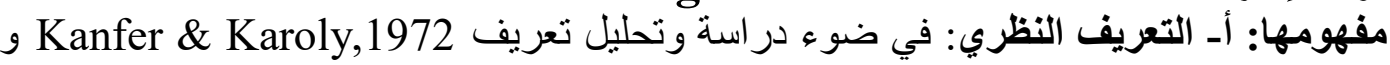

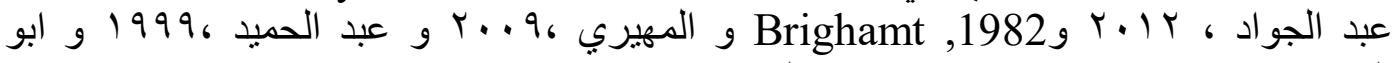

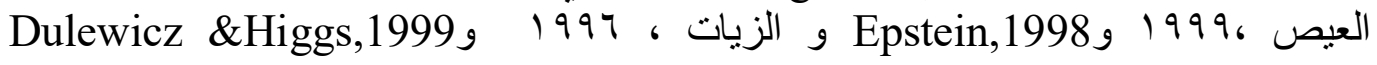


نستخلص التعريف النظري التالي :" تدريب الطلاب علي استخدام استر اتيجيات محددة لتحقيق

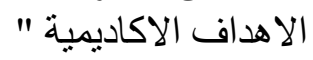

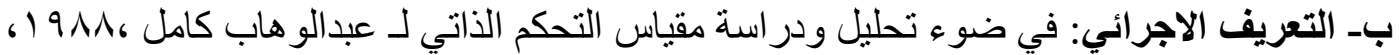

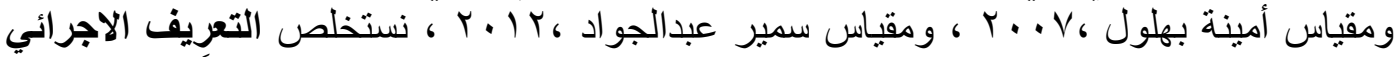

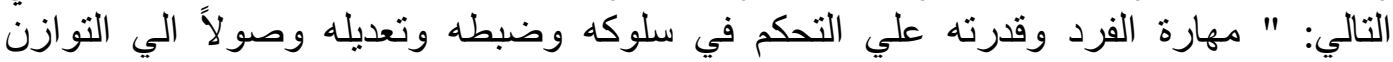

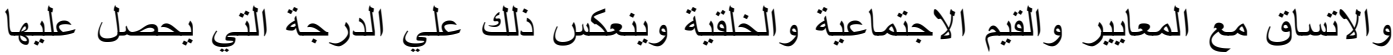

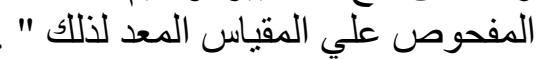

إدارة الذات والتظريات المفسرة : حظي مفهوم ادارة الذات بعرض تنظيري غير مسبوق

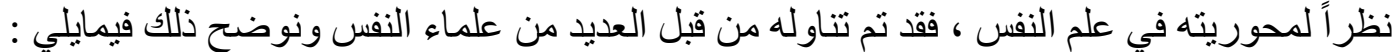
أولاً : نظرية التحكم والسيطرة : تم تطوير هذه النظرية من قبل (Carver \& Scheie,1998) ، فسلوك الافر اد يتحدد بموجب هذه النظرية من خلال الاهداف التي يضعها الفرد و الطرق التي

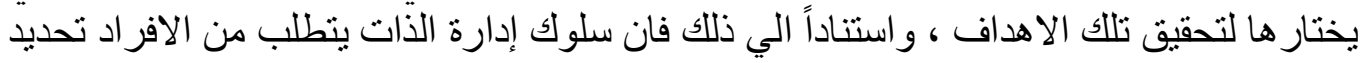

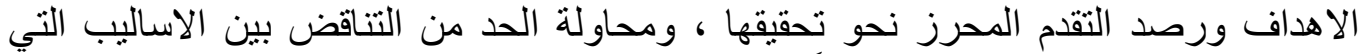

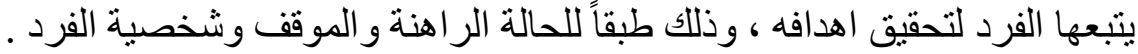

(Denise T.D \& John B.F ,2006,pp5)

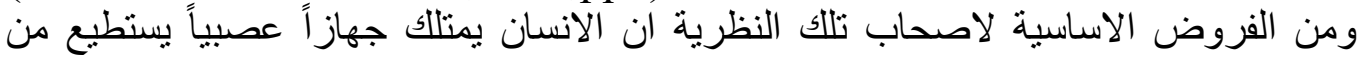

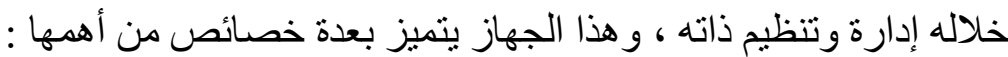
أـ ان جهاز الضبط الذاتي للسلوك قادر علي ان يبعث في نفسه الاستثارة وان يوجهان فئه حركاته بـ- يستطيع هذا الجهاز ان يتبين الفروق بين الحركات الذاتية وبين الاهداف التي يسعي اليها الفرد .

ج- ان عملية ادارة واعادة توجيه السلوك في الاتجاه المطلوب تتم بواسطه عملية التغذية الر اجعة دـ ان عملية التكامل بين أجهزة الاستقبال ( الحواس ) وبين مكونات الاستجابة المتعددة الابعاد

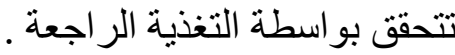
هـ - تتخصص أنماط إدارة وتنظيم الذات في ضوء التهائ الخصائص الزمنية والمكانية والعضلية

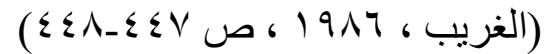

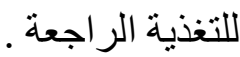

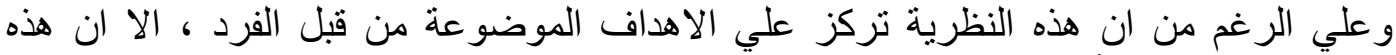

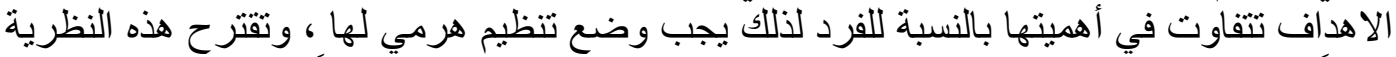

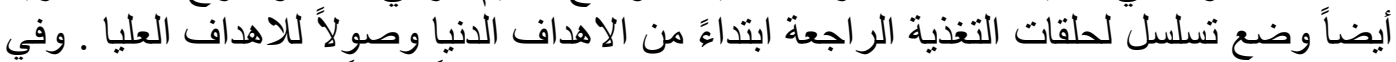

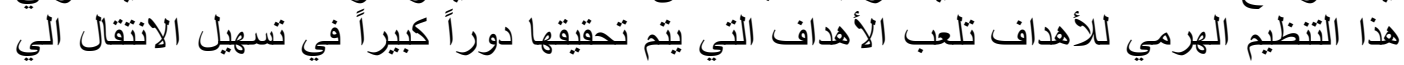

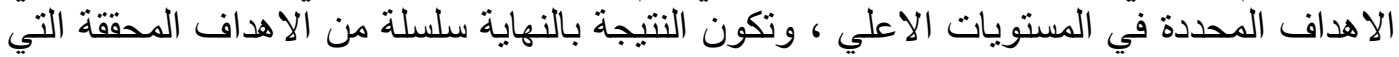

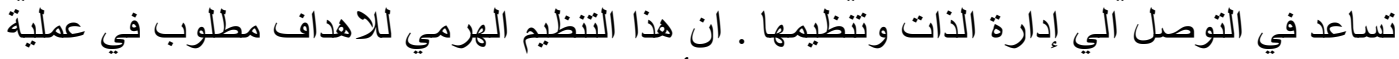

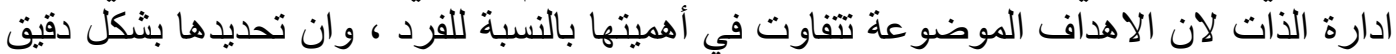

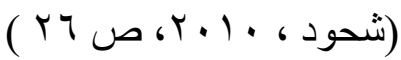

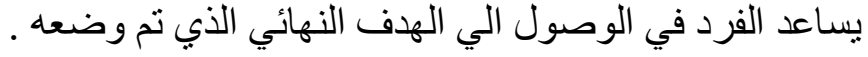

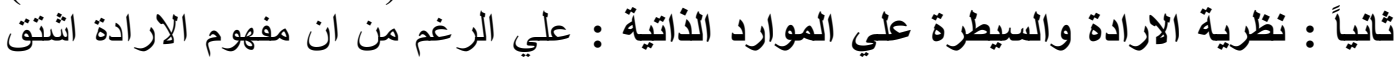

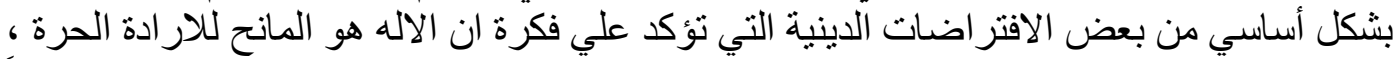

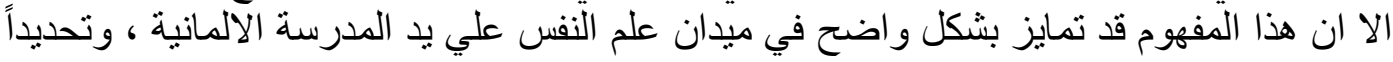

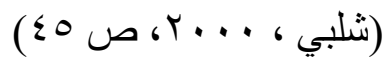

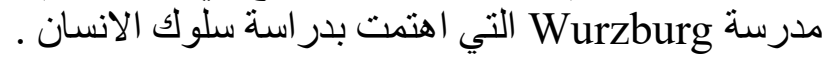


وتعرف الار ادة Will بأنها الفطرة او الرغبة الداخلية المولودة ذاتياً ، و الناتجة في صورة اختيار ات مقصودة ، وتظهر في ميل الفرد للمحافظة علي تركيزه وجهده من أجل تحقيق أَهدافه أي

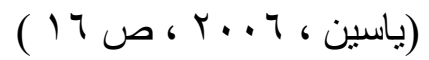

فالار ادة هي القوة الدافعة او مايدفع الفعل الي التحقق بعد ان كان في حيز التصور والتخيل ، فكل

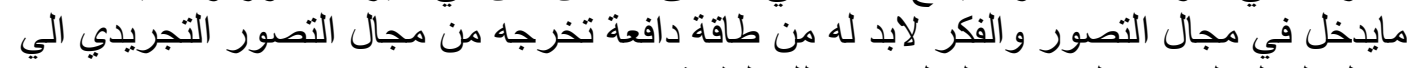

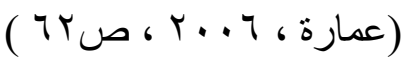

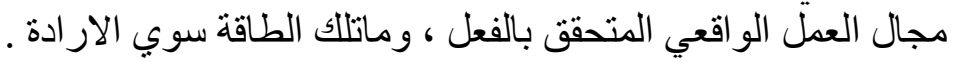
وتعتمد نظرية الار ادة في تفسير سلوك ادارة وتنظيم الذات علي الافتر اضات التالية :

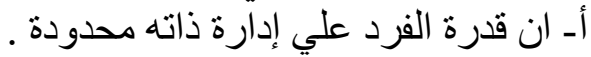

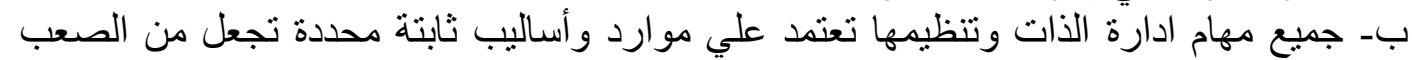

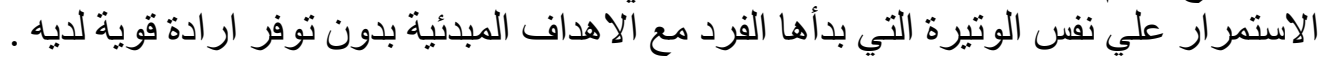

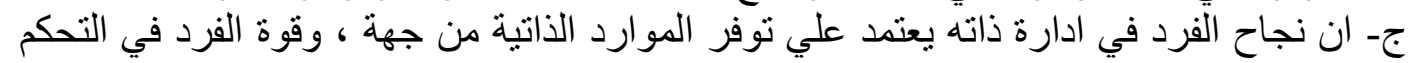

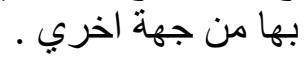

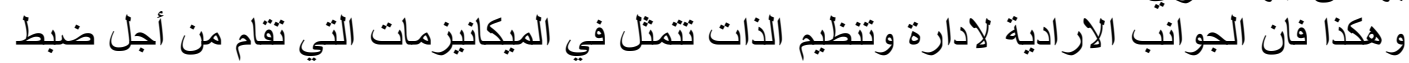

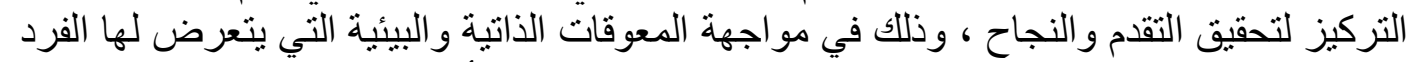

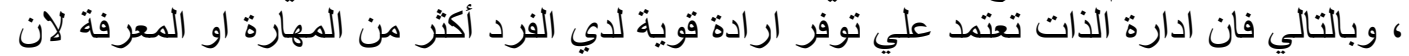

(Denise T.D \& John B.F ,2006,pp7)

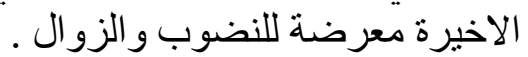

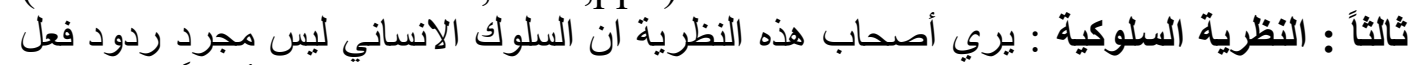

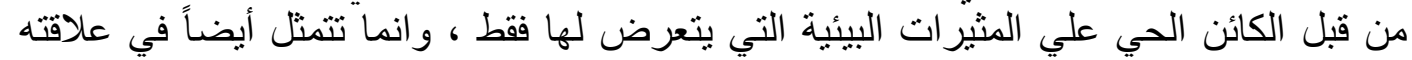

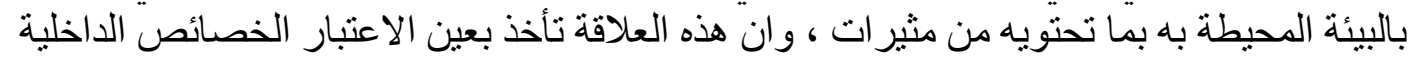
للكائن الحي ، فالكائن الحي كائن نشط يختار الاستجابات التي تتناسب مذانب مع معاييره الداخلية . (Jennifer, Suzanne Beer,2002) وتركز مجمل النظريات السلوكية علي دور الحافز في تنظيم سلوك الفرد ، و وعلي الرغم من أنها

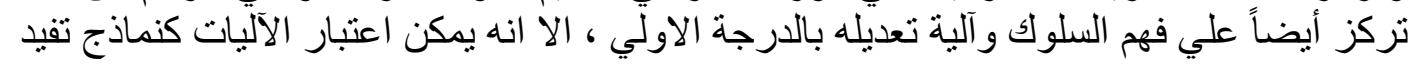

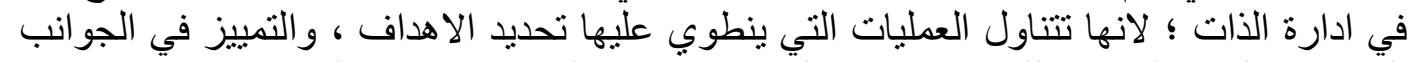

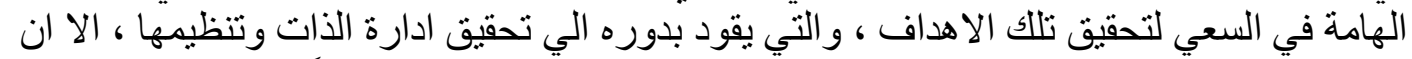

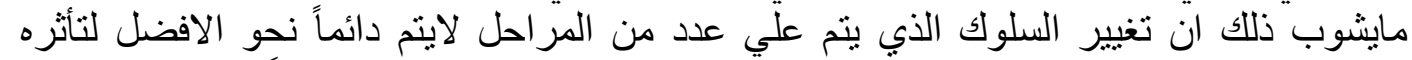

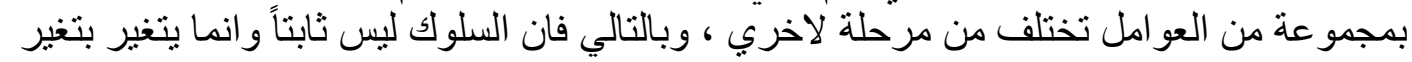

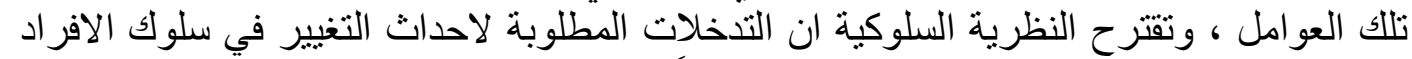

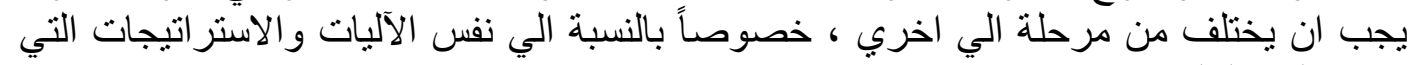

(Denise T.D \& John B.F ,2006,pp7)

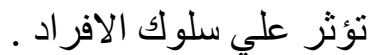

وفي ضوء ماتقدم نخلص الي ان هذه النظرية تعير الاهنمام الاكبر للحوافز في تحقيق ادارة الذات

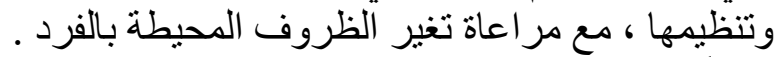

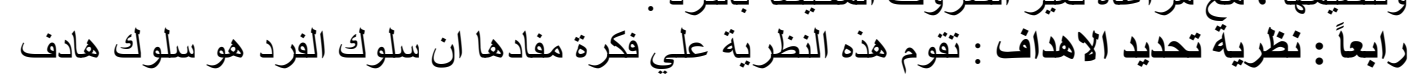

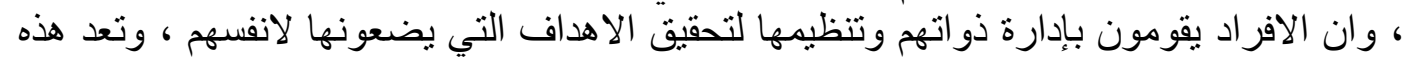

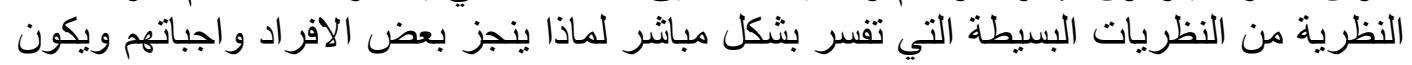


ادائهم أفضل من الآخرين ؟ حيث يعود السبب وفق هذه النظرية الي الاهداف التي يضعها الفرد

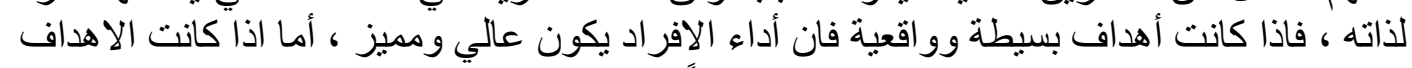

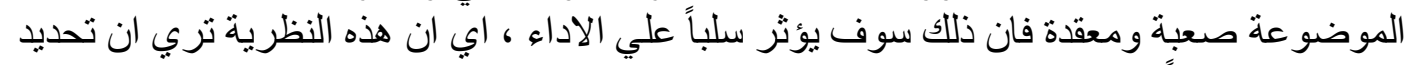

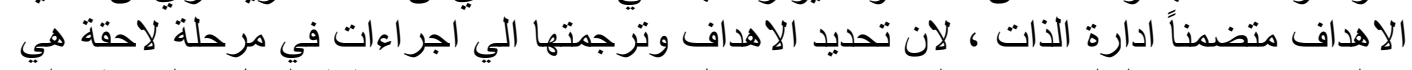

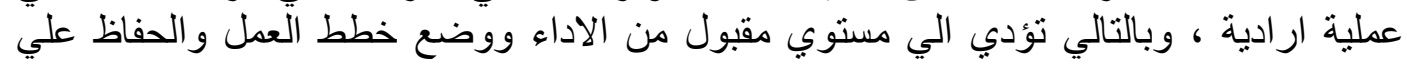

(Stanlly, Morris Gully,1997)

خامساً : النظرية الاجتماعية المعرفية : تفترض النظرية الاجتماعية المعرفية لباندورا ( IVV (

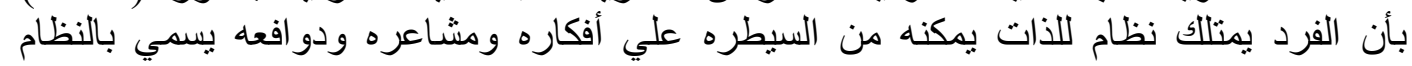
المعرفي العاطفي ، فهو يتضمن الهياكل والآليات المعرفية و المرجعية التي توفر الآلية الضرونية الضرورية

(Robert Cobb,Jr,2003)

وتؤكد هذه النظرية علي ان الافراد يمكنهم ادارة سلوكهم بفاعلية من خلال تصور اتهم واعتقاداتهم

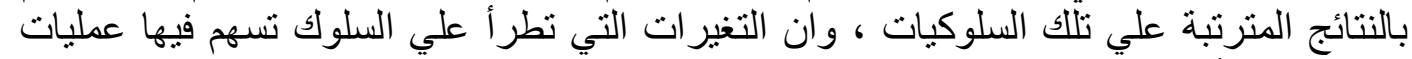

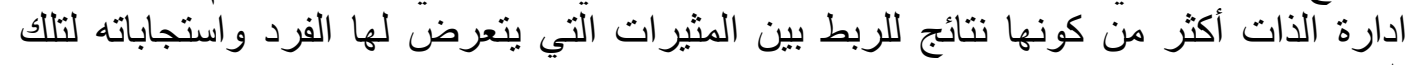

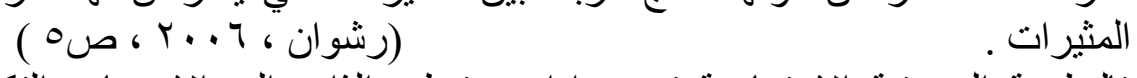

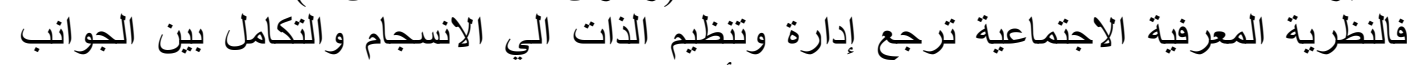

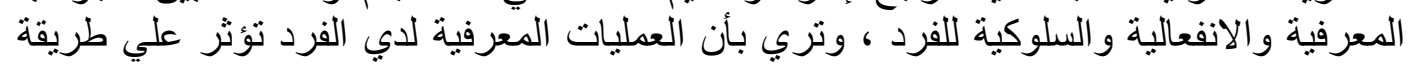

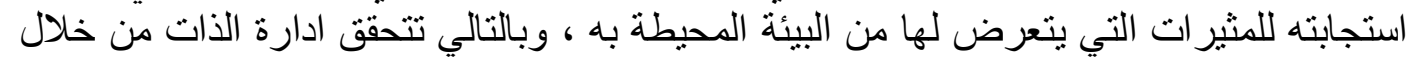

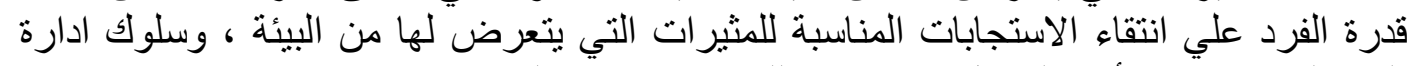

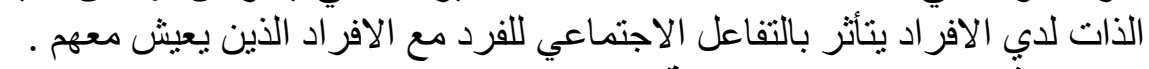

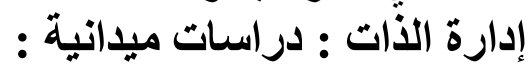

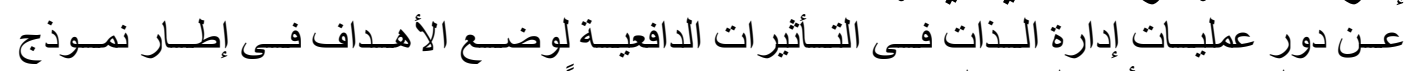

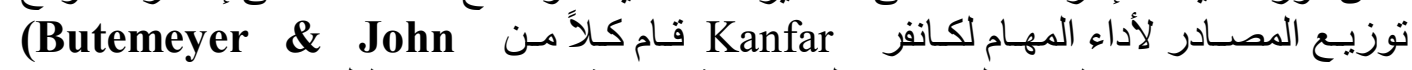

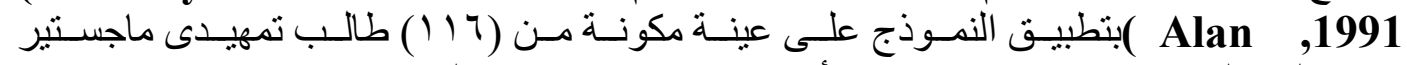

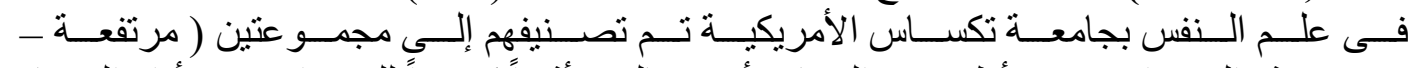

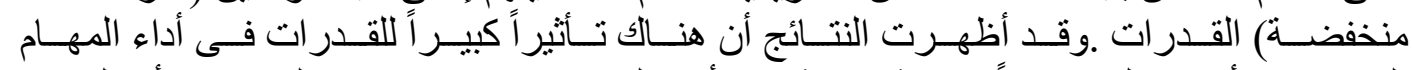

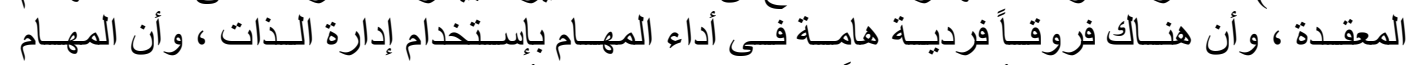

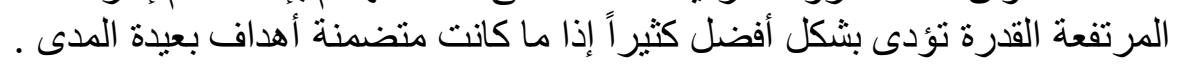

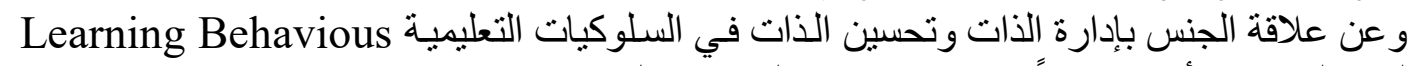

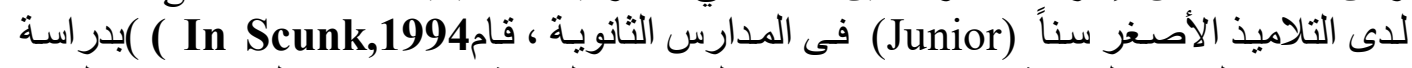

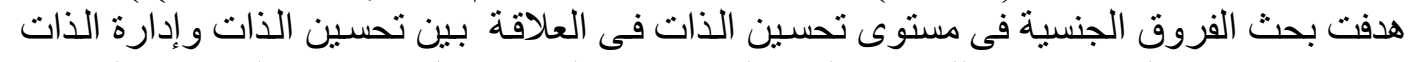

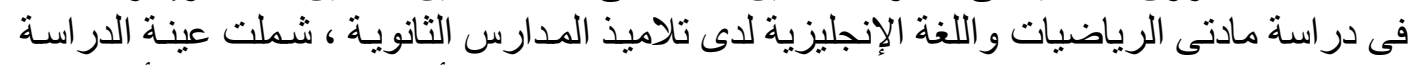

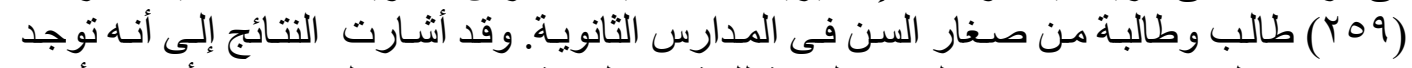

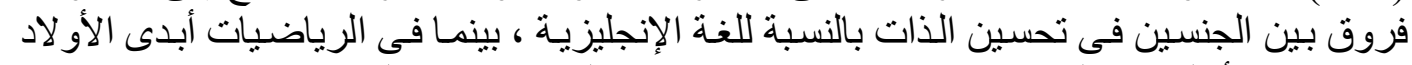

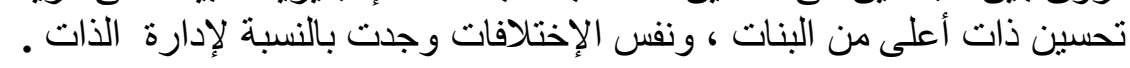

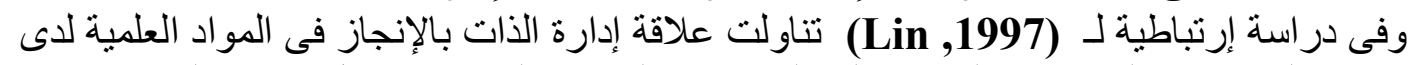

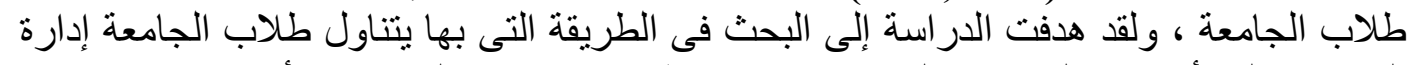

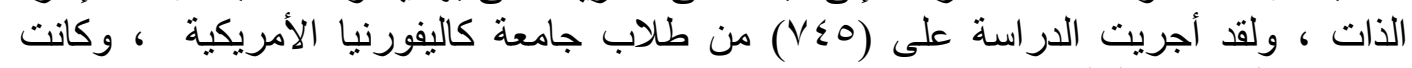

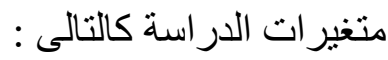

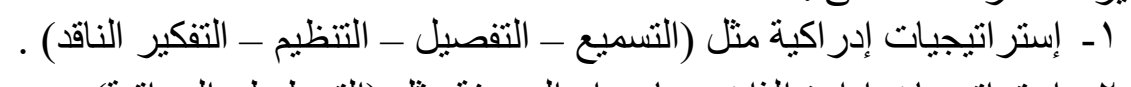
r- إستر اتيجيات إدارة الذات وما ور اء المعرفة ماتة مثل (التخطيط والمر اقبة) . 
rـ إستر اتيجيات إدارة المصدر مثل (إدارة الوقت ، ودر اسة البيئة ، تنظيم الجهد ، التركيز فى

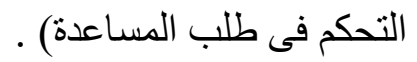

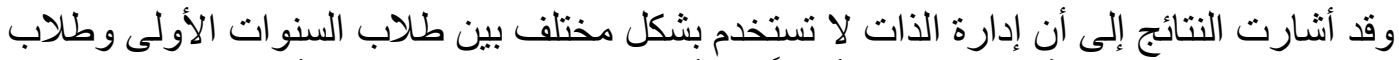

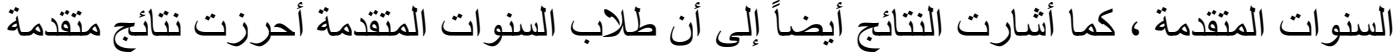

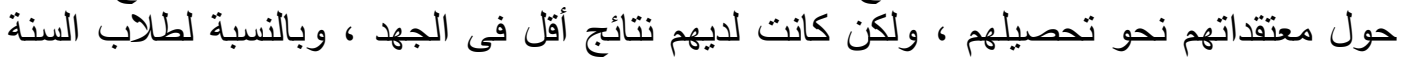

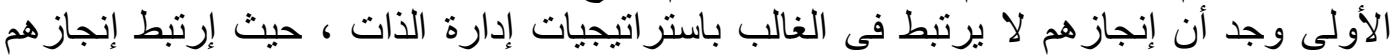
بعلاقة ضعيفة وسلبية بإدارة الذات وطلب المساعدة ، كما أن إدارة الذات لم تكن منبئة بالتحصيل

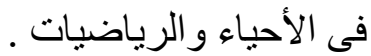

وللوقوف علي أثر التعقبدات علي إدارة الذات وتحقيق الأهداف قام (Steven Charles,2001)

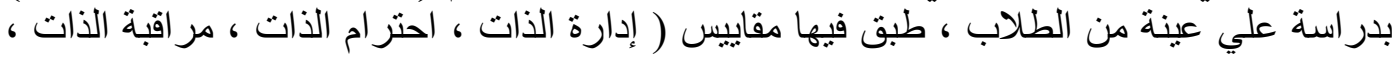

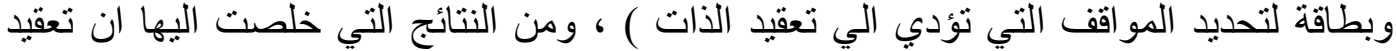

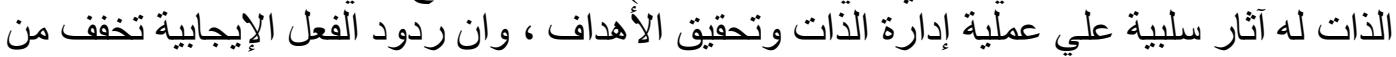

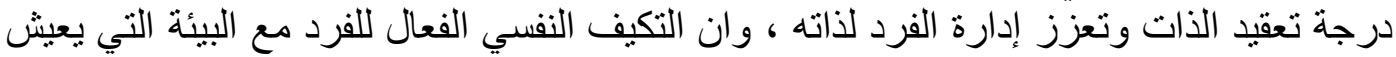

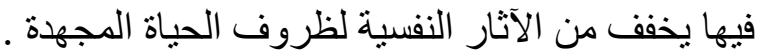

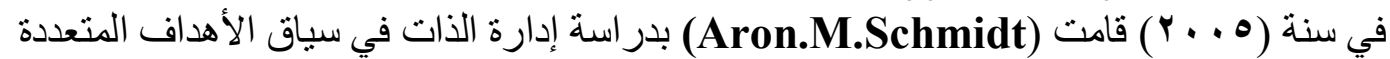
، وبينت هذه الدر اسة ان إدارة الذات تساعد الفرد علي تحسين آدائه من خلال التحة التحكم في سلوكياته ،

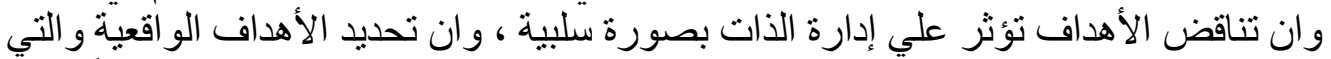
تتناسب مع القدر ات الثخصية تساعد علي إدارة الذات لدي الفرد الترد مما ينعكس ذللك إيجابياً علي

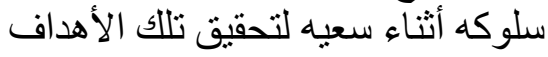

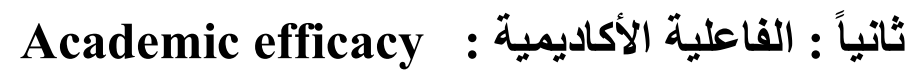

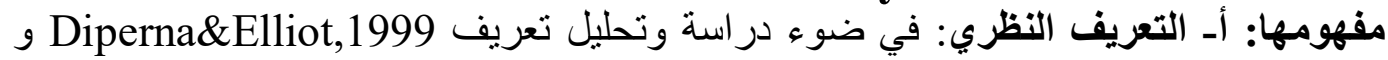
Jenkins, 1998

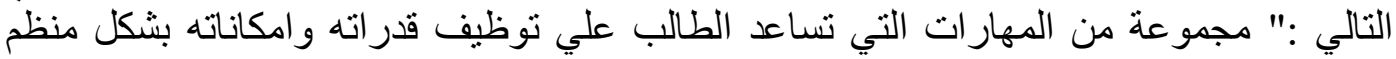

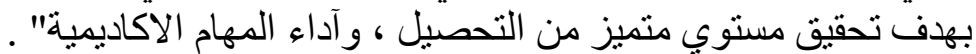
ب- التعريف الاجرائي: في ضوء تحليل ودراسة مقياس

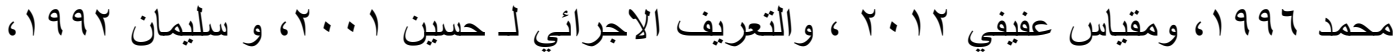

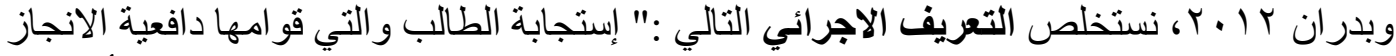

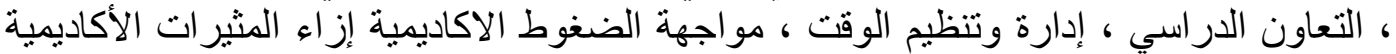

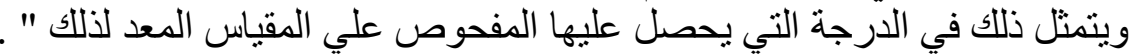

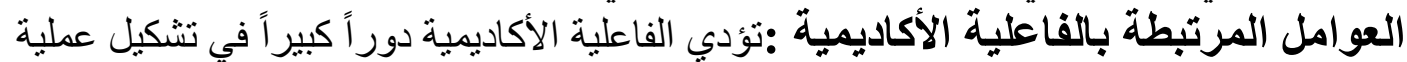

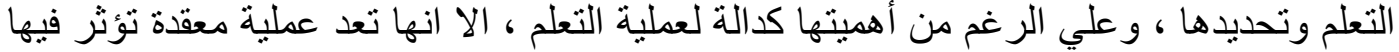

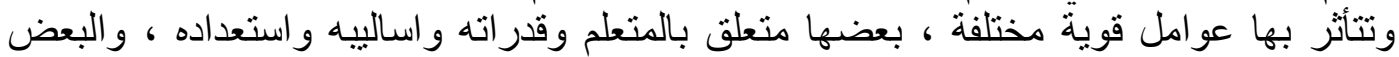

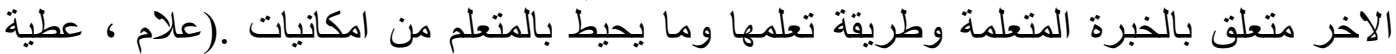

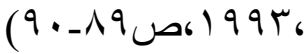

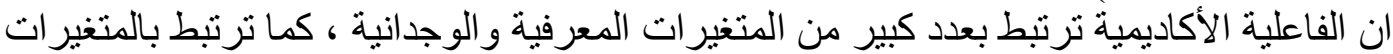

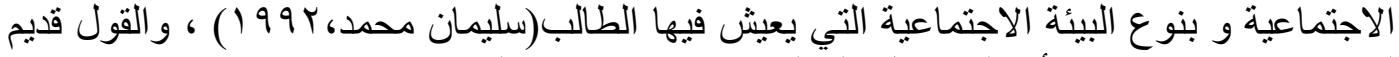

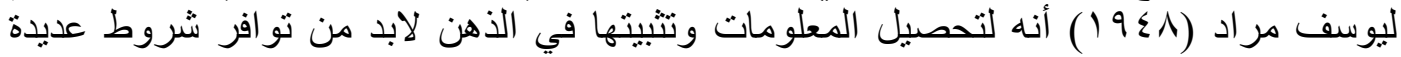

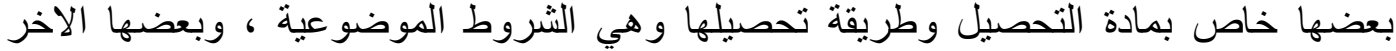

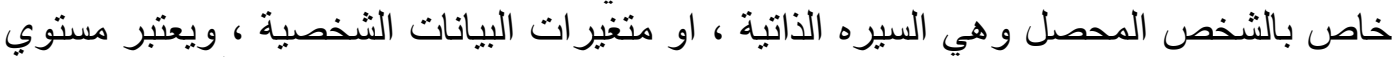

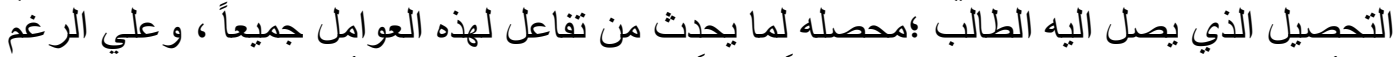
من أهمية هذه العو امل الا ان هناك احتمالاً كبيراً في تفاوتها من حيث الأهمية النسبية لكل منها ، 
وتعتبر المتغيرات الثخصية من المتغيرات الرئيسية التي تسهم بدور فعال في التنبؤ ومعرفة

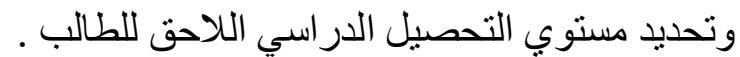

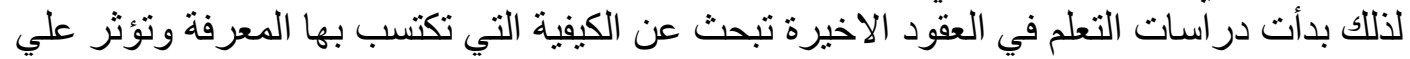

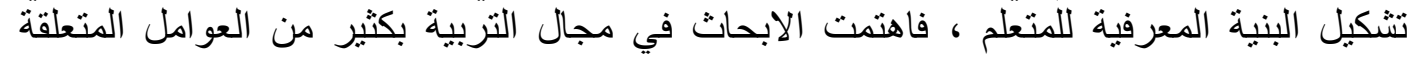

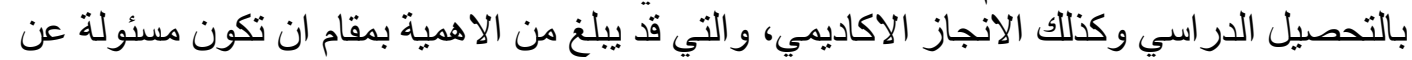

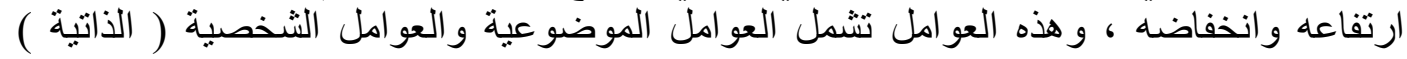
(أ) ألعوامل الموضوعية : و هي العو امل المتعلقة بطريقة التدريس ، نوع المادة التي تدرس للطالب

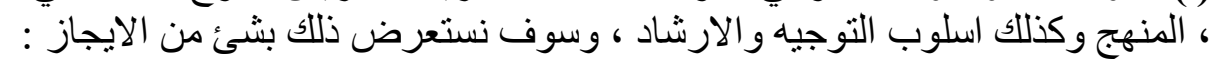

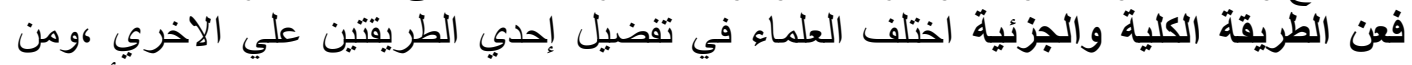

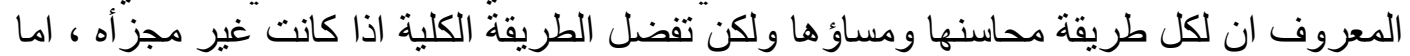

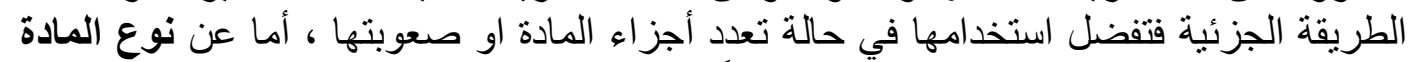

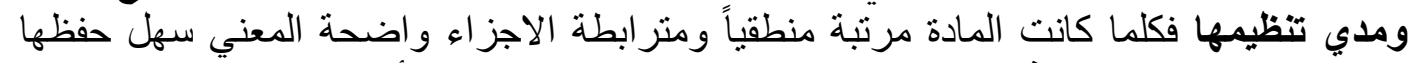

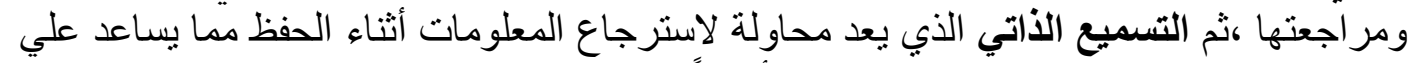

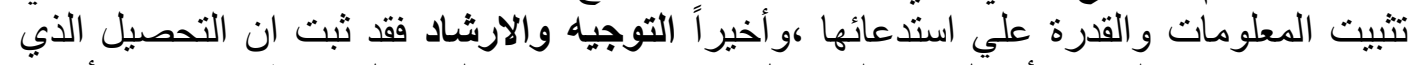

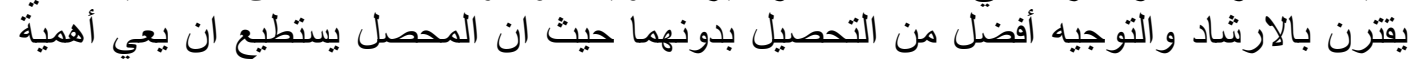

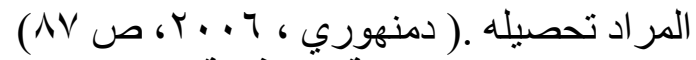

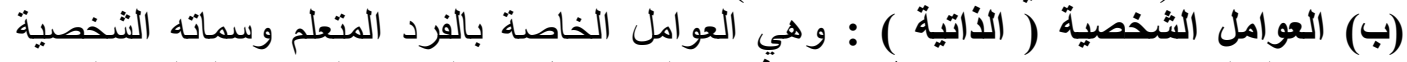

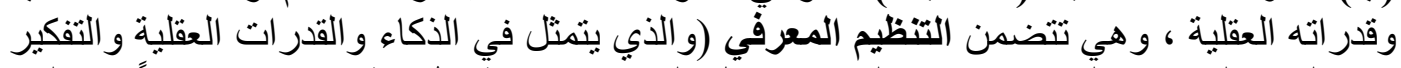

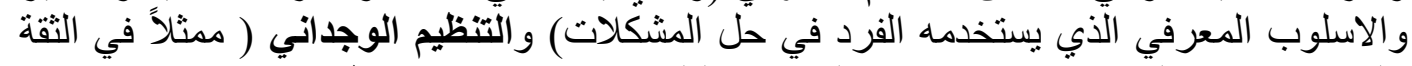

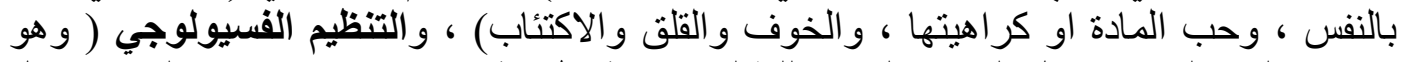

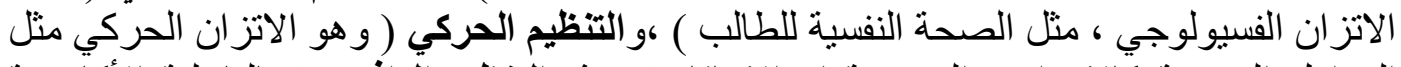

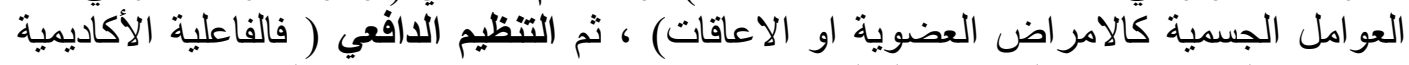

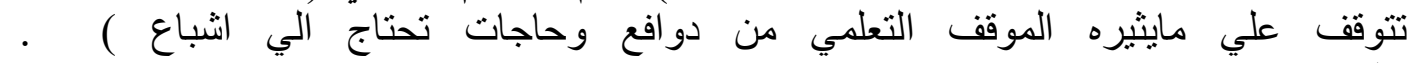

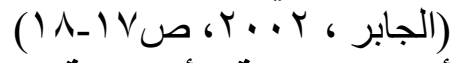
أبعاد الفاعلية الأكاديمية :اختلف الباحثون في تحديد أبعاد الفاعلية الأكاديمية ، فمنهم من حددها في بعدين و هما: البعد الأول : ويثمل المهار ات الأكاديمية ( القراءة ـ الرياضيات ـ مهار ات اللغة ـ التفكير الناقد).

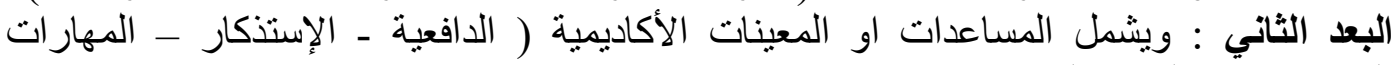

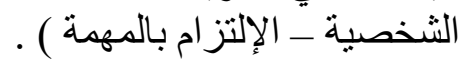

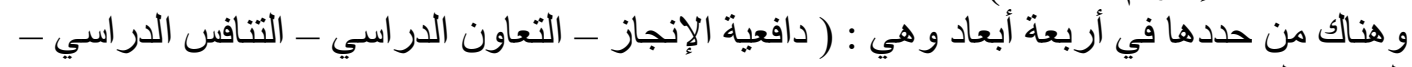

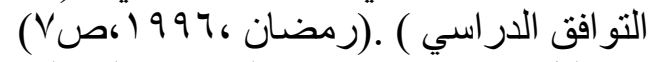

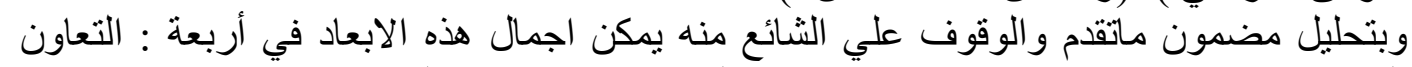

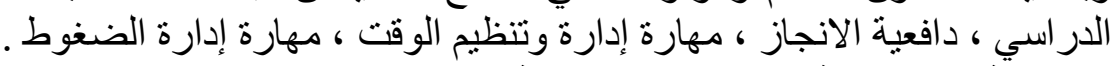

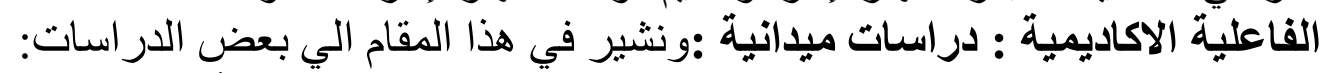

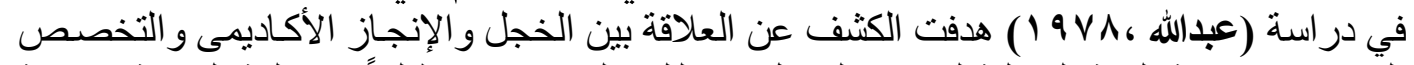

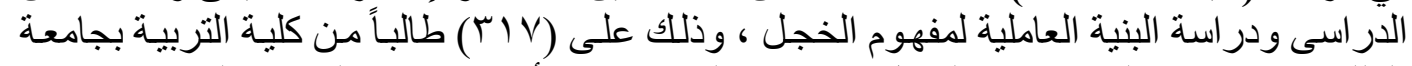

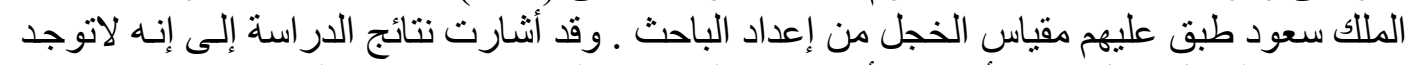

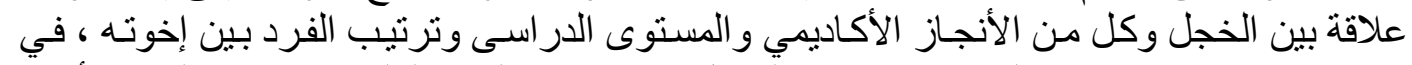

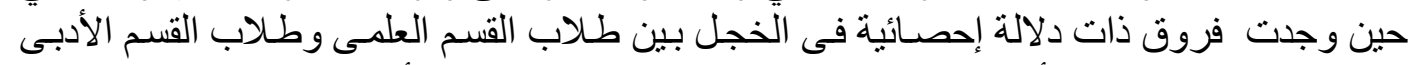

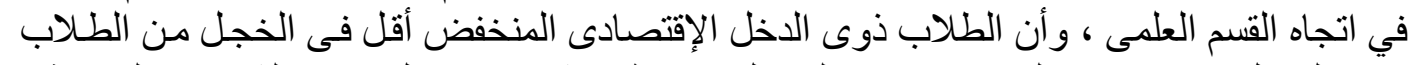

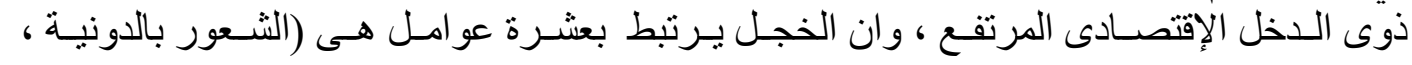


و الخوف من المو اقف الإجتماعيـة ، وتجنب الإتصـال بـالأفر اد ، وتفضيل فقدان الحقوق في سبيل

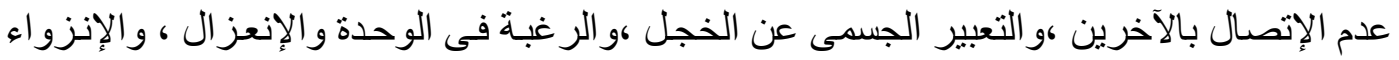

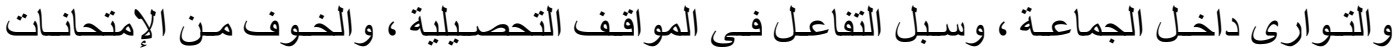

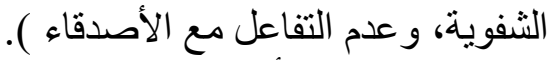
وفي نفس الاتجـاه أجري (Traub,1983) در استه للكثـف عن الإرتبـاط بين الخجل و والإكتئاب

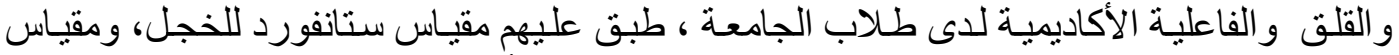

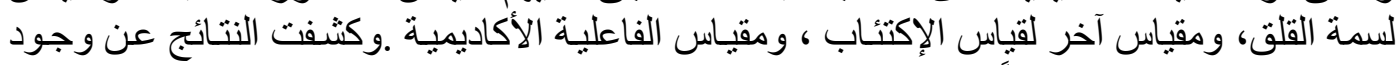

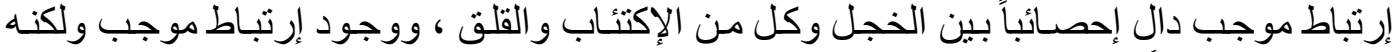

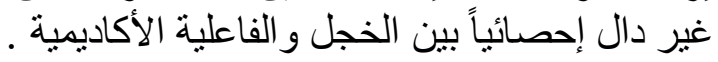

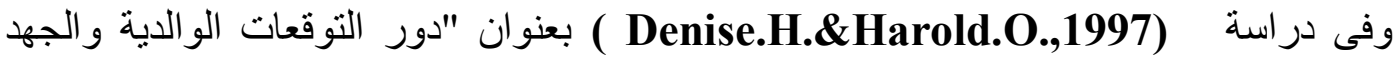

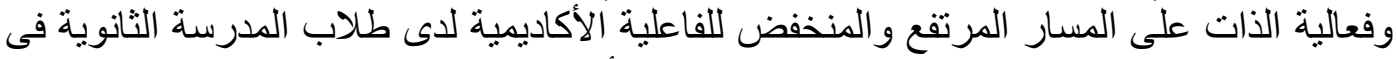
تايوان " وكان الهدف من إجراء الدراسة هو بحث أثز (إدرالك التوقعات الوالدية - expectation كســـة ) ، ( و الجهد effort - وفعالية الذات Self efficacy - و القلق المسار المرتفع و المنخفض لفاعلية الطلاب الأكاديمية .

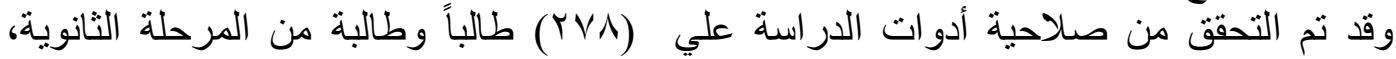

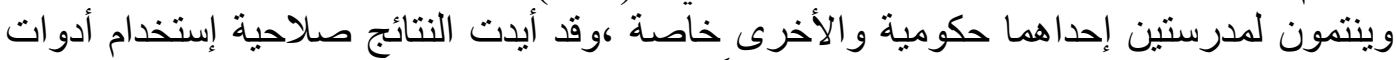

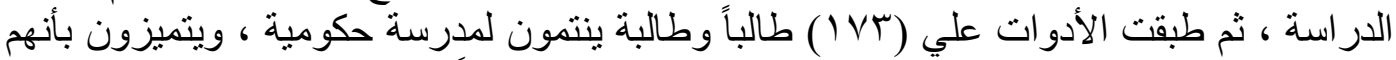

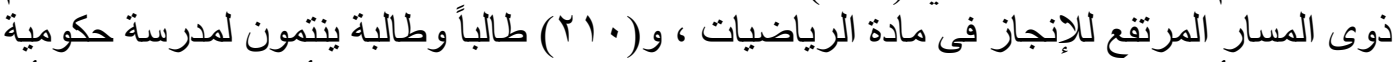

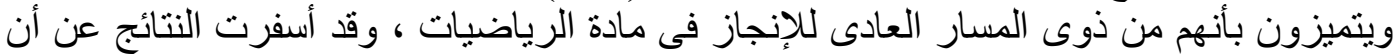

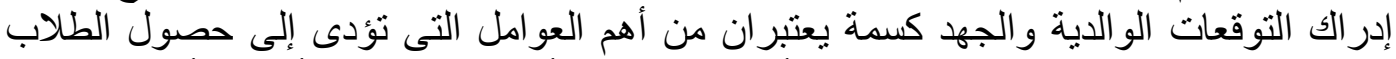

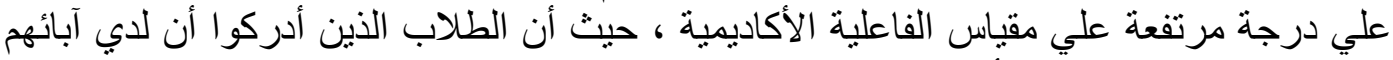

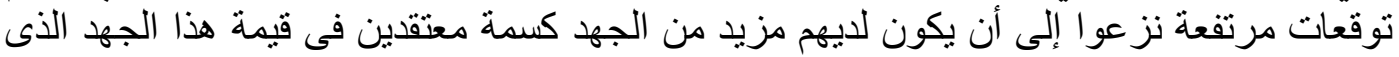

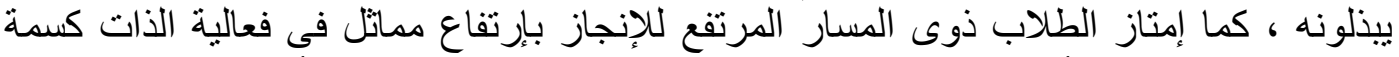

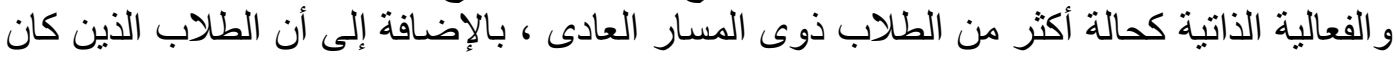

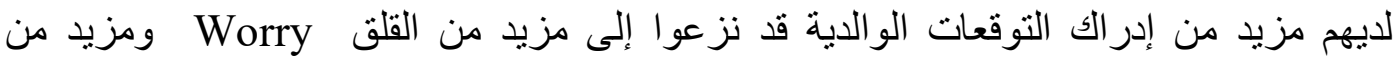

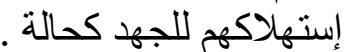

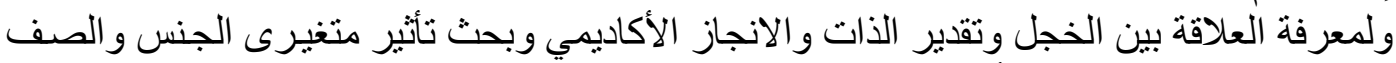

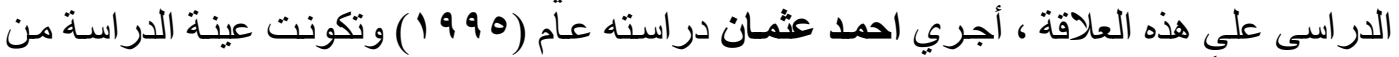

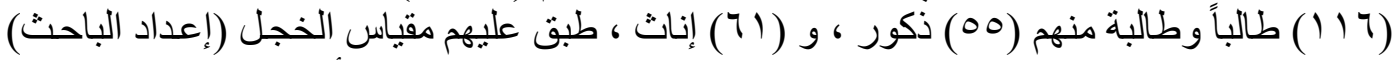

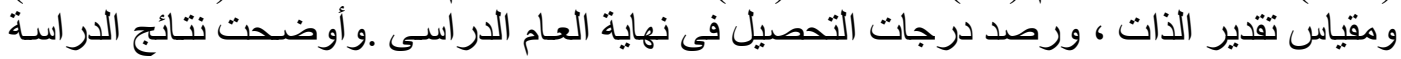

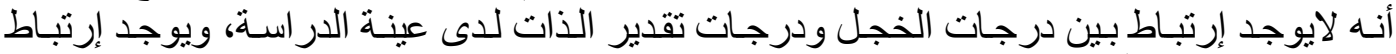

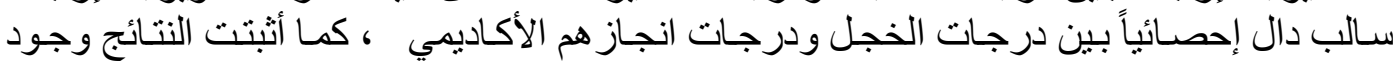

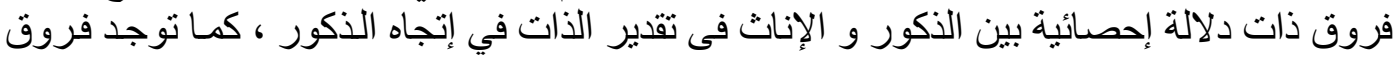

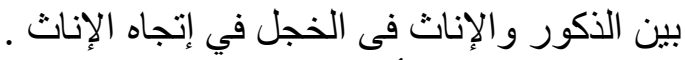

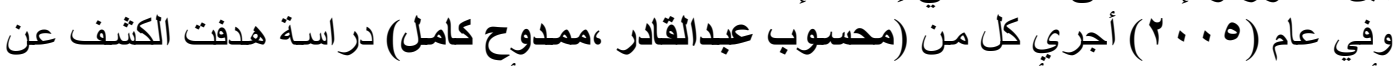

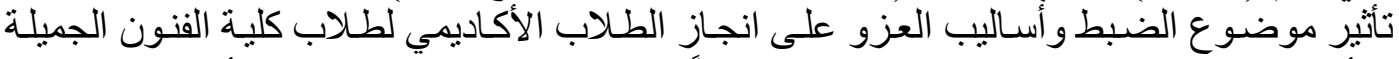

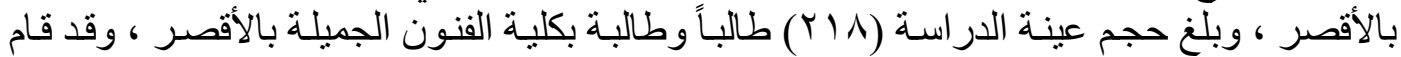

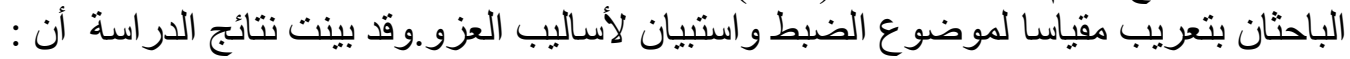

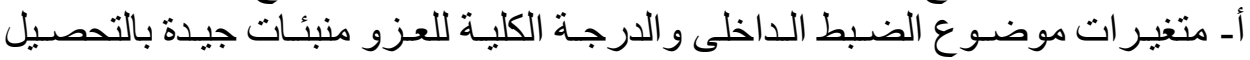

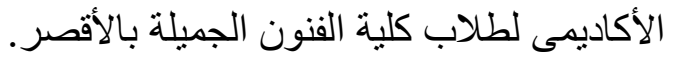

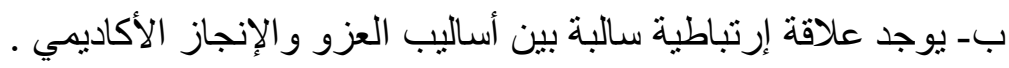


الفروض: في ضوء تحليل الاطار النظري والدراسات السابقة والوقوف علي الاهداف ومشكلة

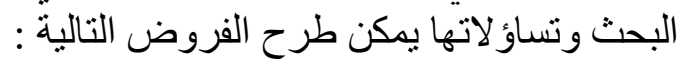

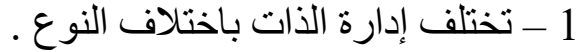

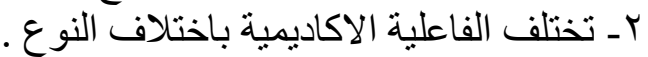

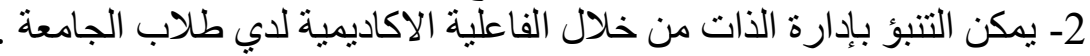

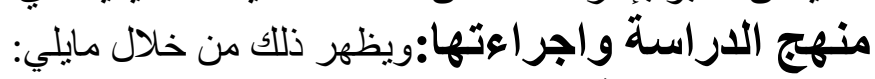
ا - إمنهج الاراسة:

تعنمد هذه الدر اسة علي المنهج الوصفي لمانلائمته لا هداف الدر اسة و عينتها وفروضها.

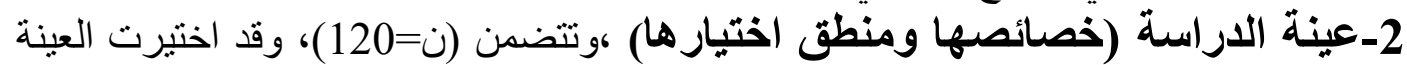

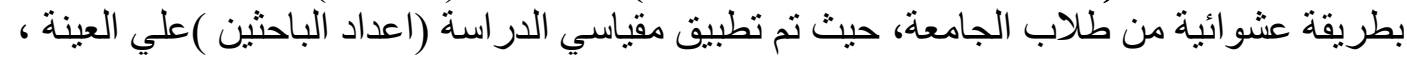

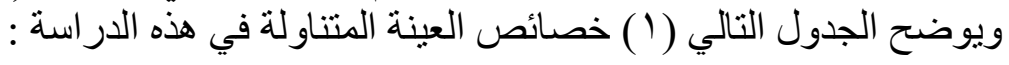

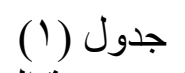

خصائص عينة الدر اسة (1)

\begin{tabular}{|c|c|}
\hline العينة & المتغير ات المستقلة \\
\hline IT. & العدد ا \\
\hline 19,0 & المتوسط العمري \\
\hline 7. & الجنس \\
\hline 7. & \\
\hline علم نفس & التخصص \\
\hline
\end{tabular}

أدوات الار استة : وتتضمن مايلي : الداسي

أولاً:مقياس إدارة الذات:تم إعداد هذا المقياس بهدف تشخيص إدارة الذات لدي طلبة الجامعة.

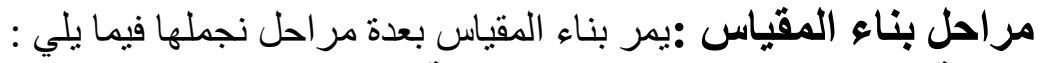

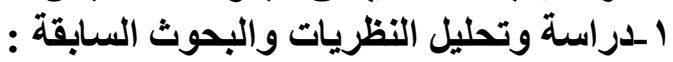

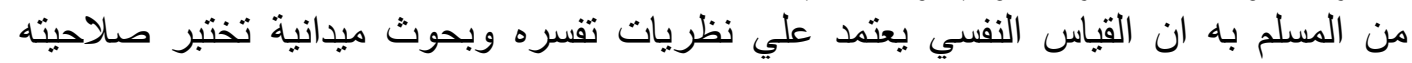

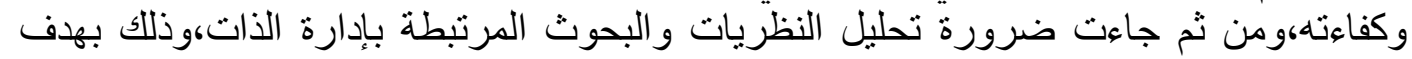

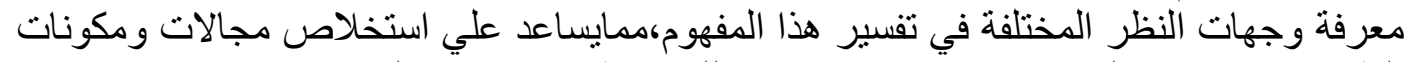

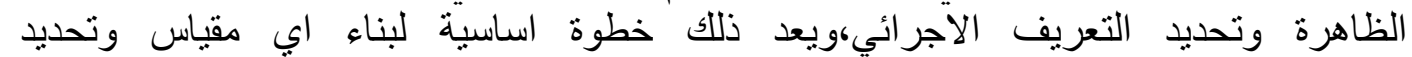
مكوناته،و الدر اسات التي تتاولت إدارة الذات كثيره نذكر منها علي سبيل المثال لا الحصر :

، Frester C.D,1965، McCombs\& Marzano,1990، McCombs,1989)

( Berger,D.S,2003،Zimmerman,1989

ץ ـالاطلاع علي المقاييس والاختبارات السابقة : تم الاطلاع علي المقاييس السابقة بهدف الاستفادة

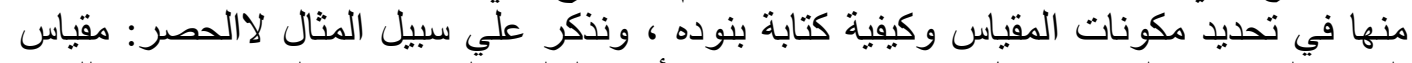

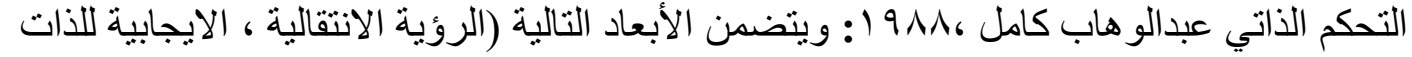

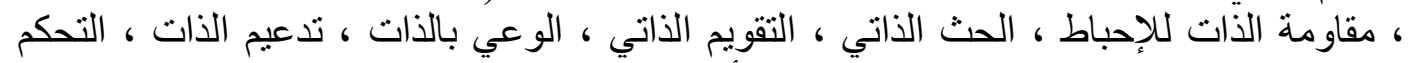

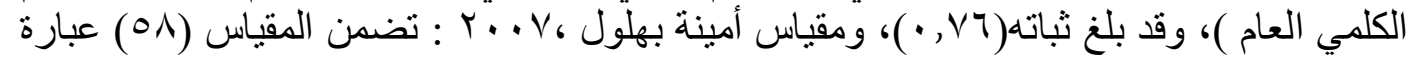

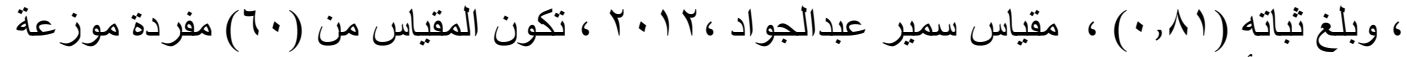

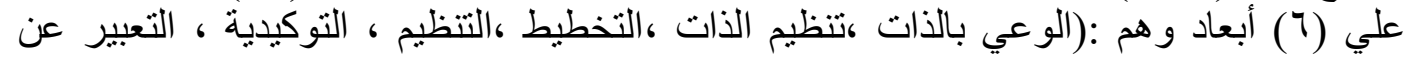

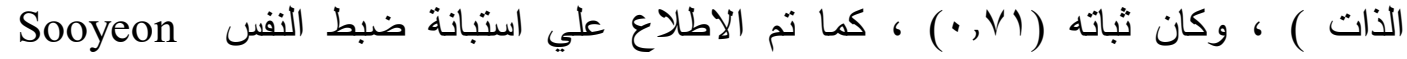


Kim\&Velma McBride,2001 ، حيث تكونت من (10) بند موز عة علي فرعين ، أولهما

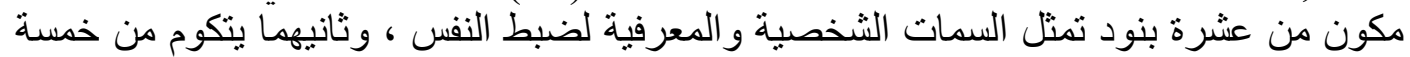

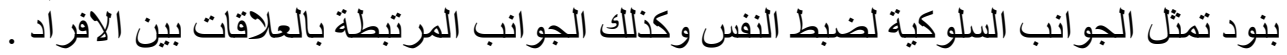
3- الاستبانة المفتوحة :

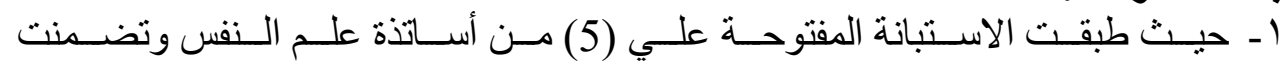

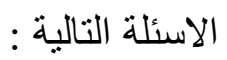

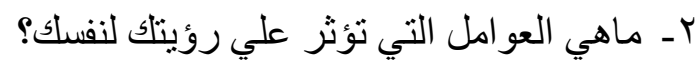

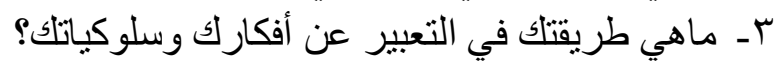

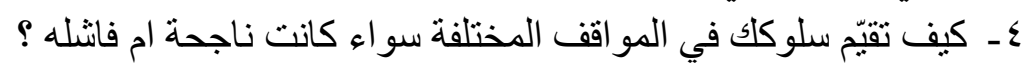
4-تكوين المفردات :

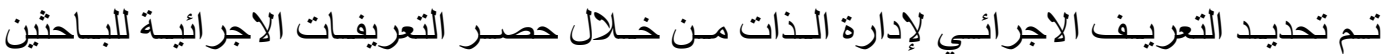
( In ، Cavendish\&Handicapping,2005 'Stoeger, H \& Ziegler, A. 2008)

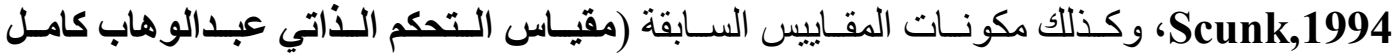

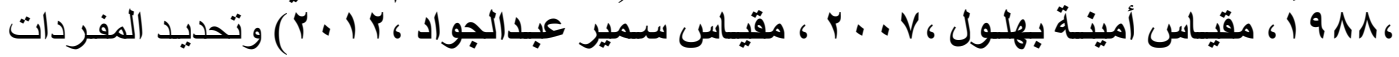

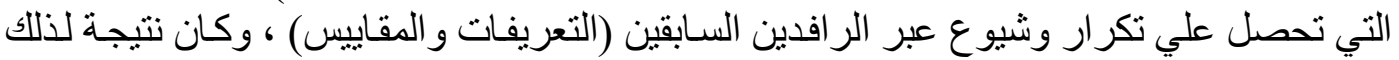

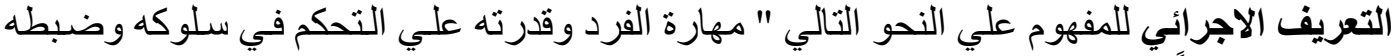

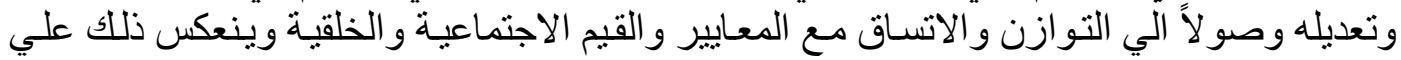

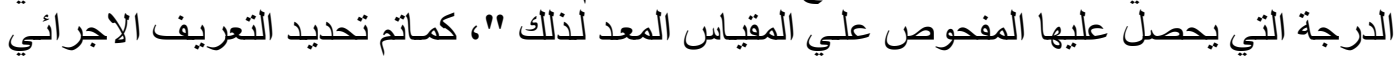

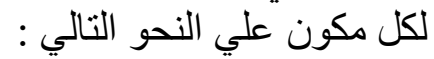
ا - رؤية الأات (ملاحظة الفرد لسلوكه عبر المواقف مع تقصي الاسباب التي تؤدي

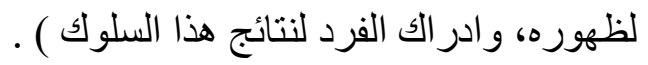

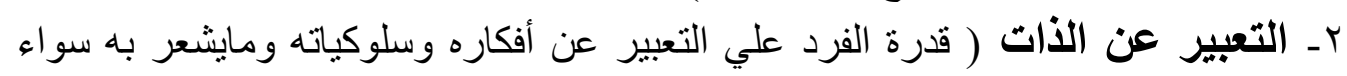

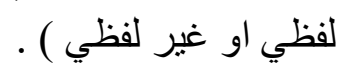
rـ تذعيم الذات (إدر الك الفرد لسلوكه مع تعزيز الايجابي ورفض السلبي ) .

هصياغة عبارات المقياس :تم صياغة مفردات المقياس في ضوء مصاد مصادر المعرفة السابقة وبناءً

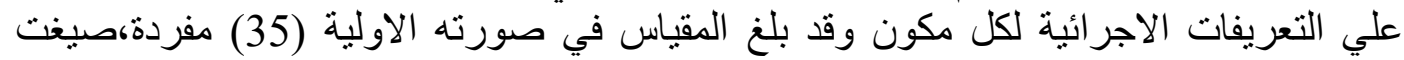

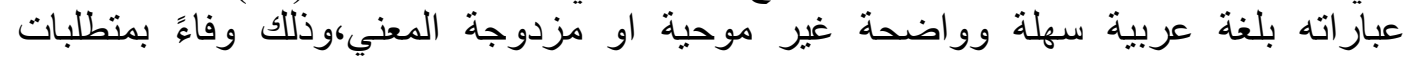

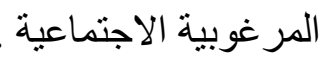

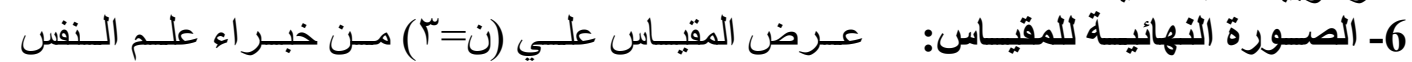

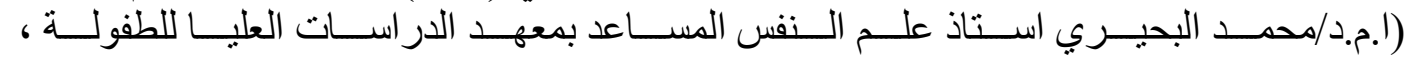

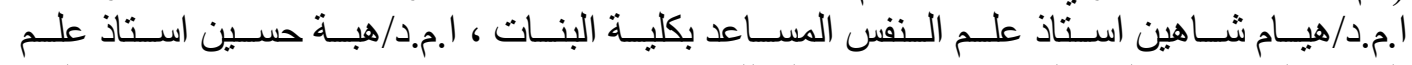

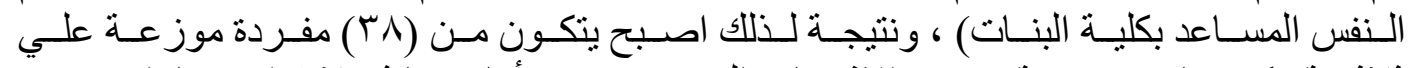

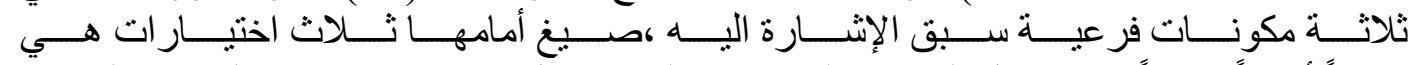

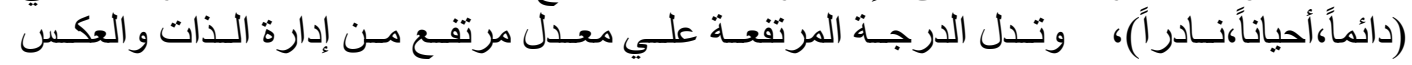

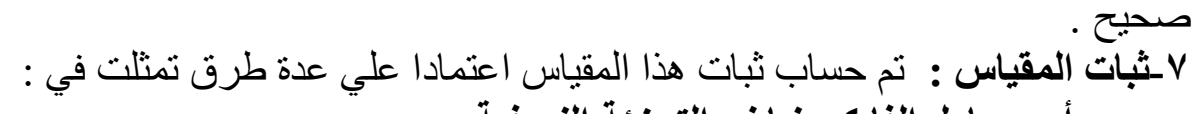
أـ معامل الفا كرونباخ والتجزئة النصفية : 


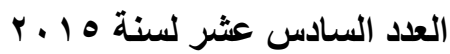
مجلة البحث العلمى فى التربية

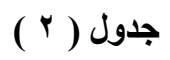

قيمة "ر" لحساب ثبات المقياس ومكوناته بطريقتي الفاكرونباخ والتجزئة النصفية

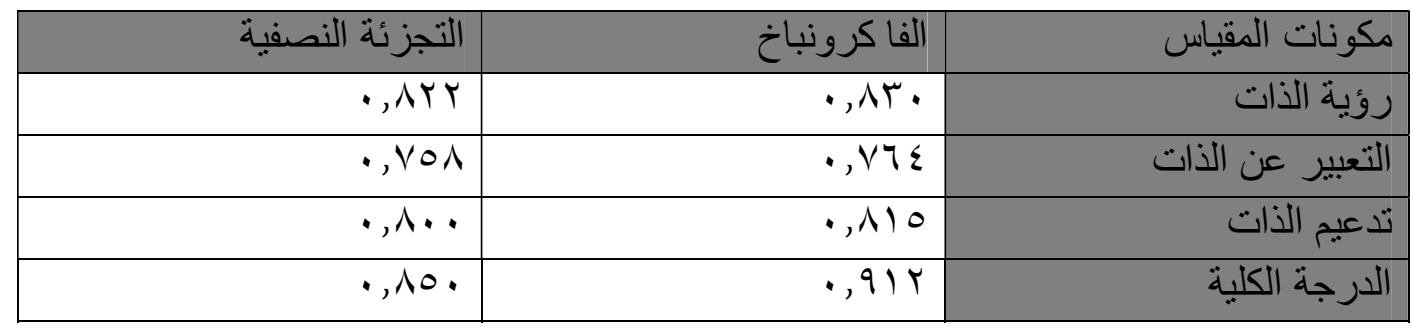

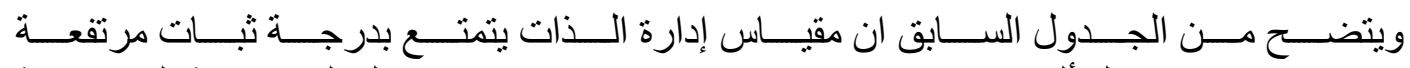

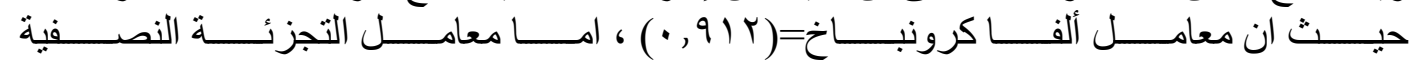

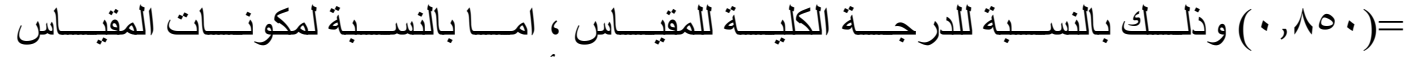

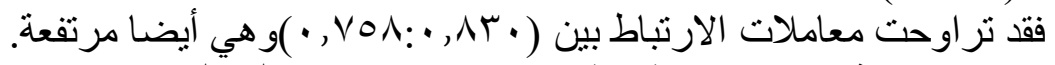

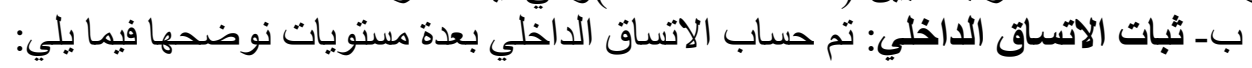

أولاً: تمّ حساب الإرتباط بين درجة البنود والارجة الكلية للمقياس بهدف الإطمئنان لاستقرار

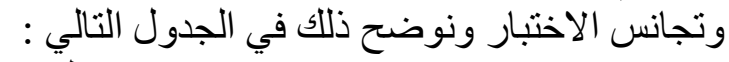
جدول (ب) الأن قيم معاملات الارتباط بين مكونات إدارة الذات والارجة الكلية لحساب الثبات بطريقة الاتساق الاخلي (ر) الباتي

\begin{tabular}{|c|c|c|c|c|c|c|c|}
\hline قيمة (ر) & رقم البند & قيمة (ر) & رقم البند & قيمة (ر) & رقم البند & قيمة (ر) & رقم البند \\
\hline - , & M & •, Yフ** & rI & - , $\leqslant 9 * *$ & 11 & $\cdot, 11 * *$ & 1 \\
\hline -,$\leqslant 7 * *$ & rr &., $09 * *$ & rr & $\cdot, \Pi \wedge * *$ & 14 & •,$\uparrow \vee * *$ & r \\
\hline$\cdot, r \leq * *$ & r & $\cdot, r \leqslant * *$ & r & •, イ** & $1 \%$ & • , & $r$ \\
\hline • , $\leqslant * * *$ & $r \varepsilon$ & -,$\leqslant 9 * *$ & $r \varepsilon$ & -,$\varepsilon \vee * *$ & $1 \varepsilon$ & •, & $\varepsilon$ \\
\hline •,$\Gamma \leqslant * *$ & ro & • & ro & $\cdot, 07 * *$ & 10 & •, ケ৭** & 0 \\
\hline$\cdot, r \vee * *$ & q & • & rq & $\bullet, 0 \wedge * *$ & 17 & $\cdot, \zeta \mid * *$ & 7 \\
\hline •, $\neg \vee * *$ & rV & •, & $r V$ & • & $1 V$ & •, ケフ** & V \\
\hline \multirow[t]{3}{*}{ • , } & rᄉ & •, イ०** & r人 & •, ケฯ** & 11 & $\cdot, r \vee * *$ & $\wedge$ \\
\hline & & • & rq & $\cdot, \neg \wedge * *$ & 19 & $\cdot, Y \mid * *$ & 9 \\
\hline & & • & r. & •, ґ०** & r. & $\cdot, 17 * *$ & 1 \\
\hline
\end{tabular}

ثانياً : حساب الإتساق الاخلي بين درجة البند والدرجة الكلية للمكون ، ونوضح ذلك في الجدول التالي : 
جدول ( ) الفون )

قيم (ر) بين درجة البند ودرجة المكون الفرعي الذي ينتمي إليه في مقياس إدارة الذات

\begin{tabular}{|c|c|c|c|c|c|}
\hline \multicolumn{2}{|c|}{ تدعيم الذات } & \multicolumn{2}{|c|}{ التعبير عن الذات } & \multicolumn{2}{|c|}{ رؤية الذات } \\
\hline قيمة (ر) & رقم البند & قيمة (ر) & رقم البند & قيمة (ر) & رقم البند \\
\hline$\cdot, 09 * *$ & r & $\cdot, 00 * *$ & $r$ & -,$\Gamma \vee * *$ & 1 \\
\hline - , $\leqslant \leqslant * *$ & $\varepsilon$ & - , $70 * *$ & 7 & - , $\leqslant . * *$ & 0 \\
\hline - , $70 * *$ & V & -,$\leqslant 0 * *$ & 1 &., $0 \wedge * *$ & 9 \\
\hline • & $\wedge$ & - , $\leqslant Y * *$ & $1 \varepsilon$ & • & $1 T$ \\
\hline -, $0 \leqslant * *$ & 11 &., $07 * *$ & 11 & - , $\leqslant \vee * *$ & $1 \mathrm{~V}$ \\
\hline • & ) r &., $07 * *$ & rr & - & r) \\
\hline ., $0 \vee * *$ & 10 & - & $r q$ & - ro** & ro \\
\hline - rq** & 17 & - , $\leqslant 7 * *$ & r. & 1, $0 \leqslant * *$ & rq \\
\hline -,$\leqslant \leqslant * *$ & 19 & - , $\leqslant 0 * *$ & re & •, & س \\
\hline - , $0 \vee * *$ & $r$. & & rV & & \\
\hline$\cdot, \leqslant \mid * *$ & r & & & & \\
\hline ., $07 * *$ & $r \varepsilon$ & & & & \\
\hline -,$q^{\prime} * *$ & rV & & & & \\
\hline -,$\leqslant \wedge * *$ & rᄉ & & & & \\
\hline -,$\leqslant\rceil * *$ & ו & & & & \\
\hline -, $0 \leqslant * *$ & Tr & & & & \\
\hline - , $\leqslant Y * *$ & To & & & & \\
\hline -,$\leqslant 9 * *$ & ry & & & & \\
\hline., $07 * *$ & rᄉ & & & & \\
\hline
\end{tabular}

8-صدق المقياس: تم الاعتماد علي عدة طرق للتحقق من صدق المقياس وهي :

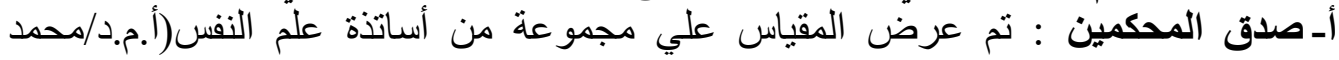

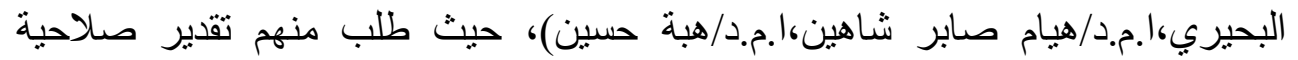

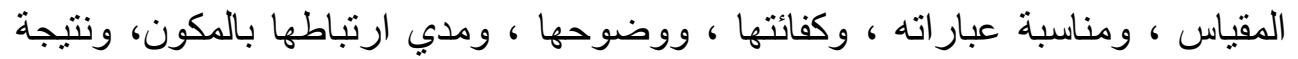

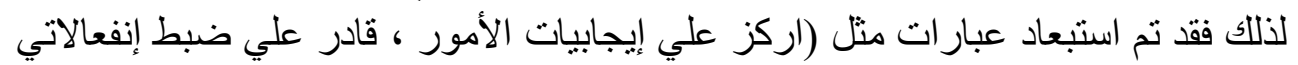

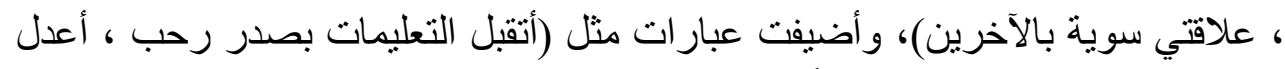

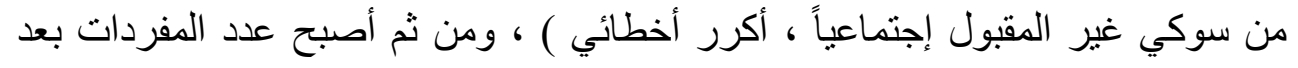

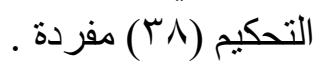

بـ صدق المحتوي (البناء والتكوين) : ويقصد به مدي تمثيل المقياس للظاهرة التي يضطلع

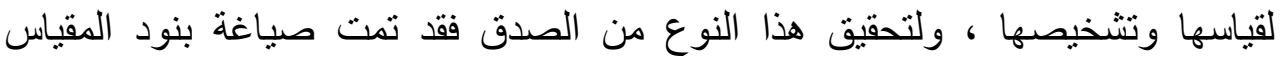

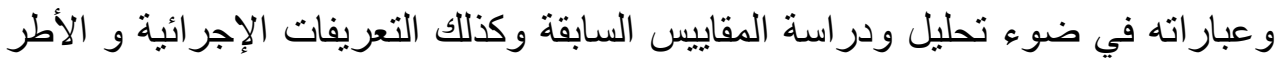

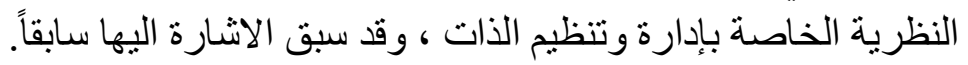

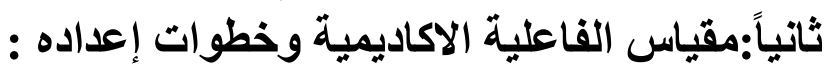

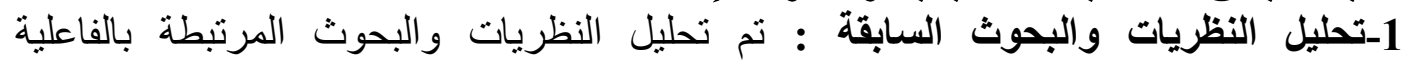
الاكاديمية،وذلك بهدف معرفة وجهات النظر المختلفة في تفسير هذات المفهوم،ممايساعد علي 
استخلاص مجالات ومكونات الظاهرة ،ويعد ذلك خطوة اساسية لبناء المقياس النفسي وتحديد

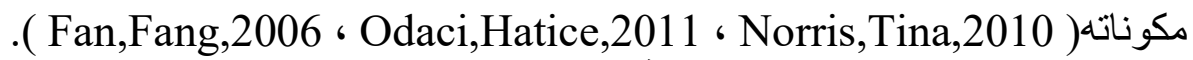

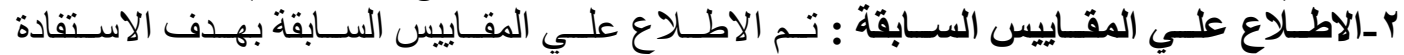

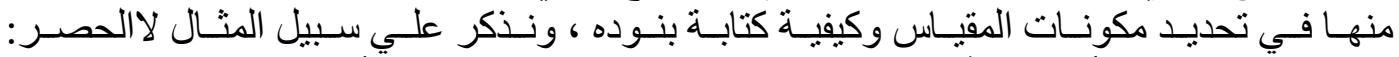

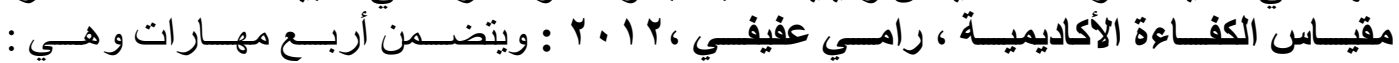

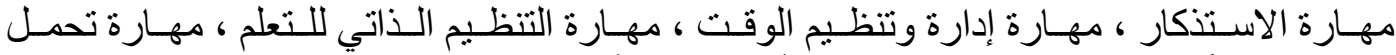

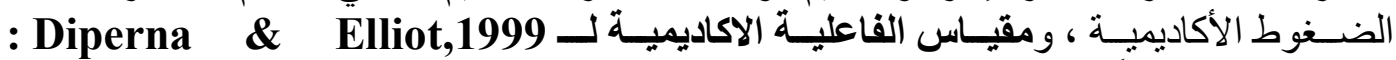

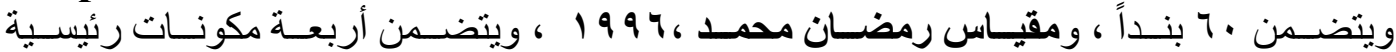

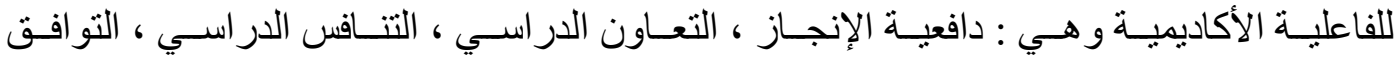

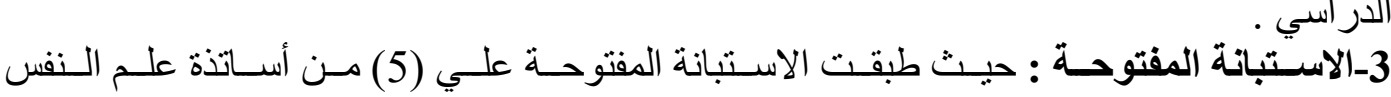

وتضمنت الاسئلة التالية :

๑ـ ما العو امل التي تزيد من قدرة الفرد علي اداء عمل ؟

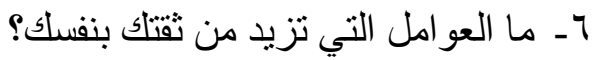

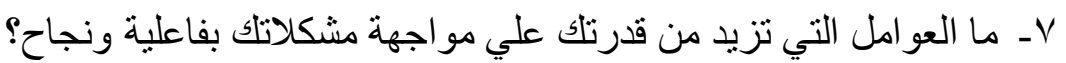

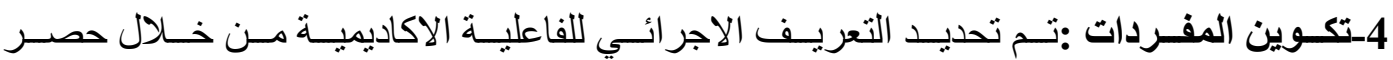
، Gaythwaite, 2006 التعريفـات الاجر ائيـة للبـاحثين (Rosario et,al,2004،

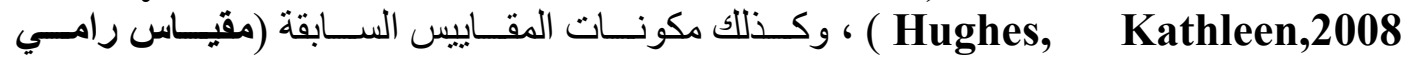

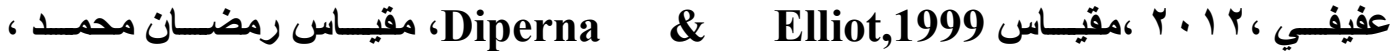

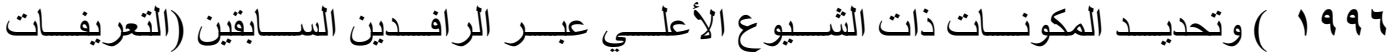

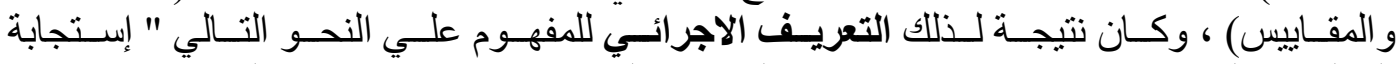

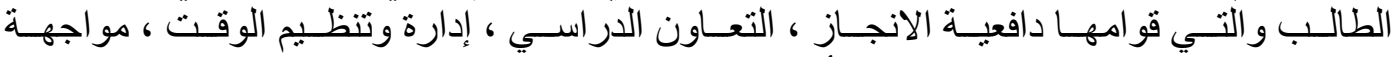

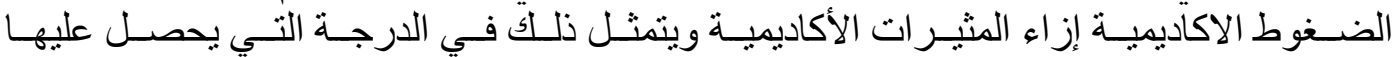
المفحـوص علـي المقيـاس المعـد لـذللك " ، كمـاتم تحديـد التعريـف الاجر ائسي لكـل مكـون علـي

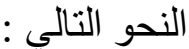

ا ـ دافِّية الأنجاز :سعي الفرد الي تحقيق التفوق والاعتزاز بالنفس واحترام الذات.

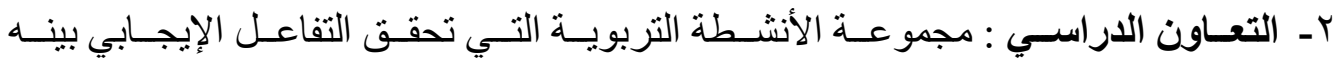
وبين الزملاء.

r- إدارة وتتظيم الوقت : استثمار الوقت بشكل فعال ومحاولة تقليل الوقت الضائع.

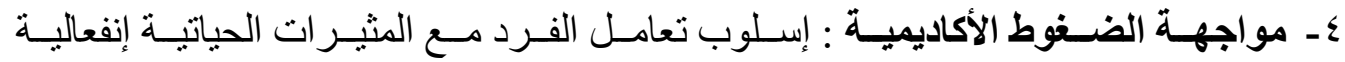
كانت او عقلية او سلوكية بأساليب إيجابية او سلبية .

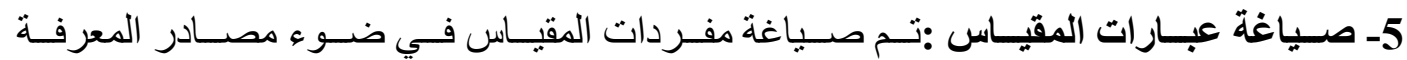

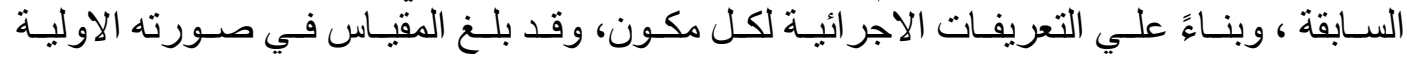

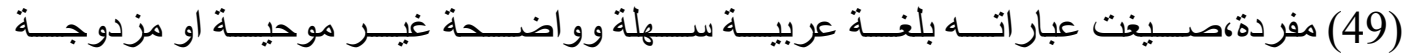

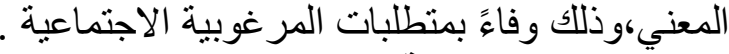

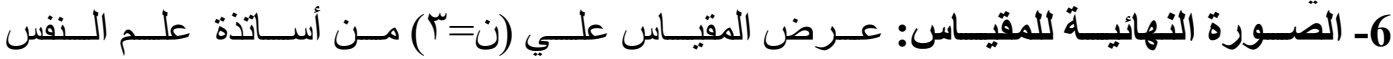

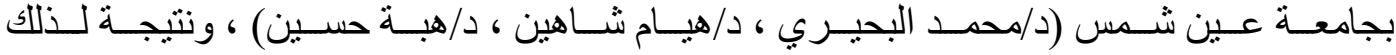

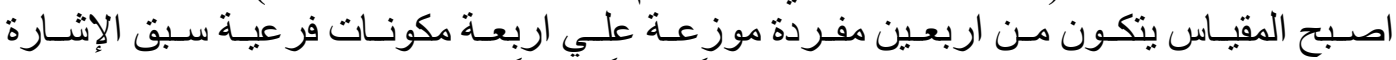

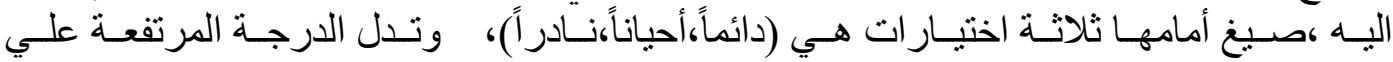

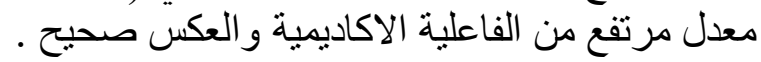


9.

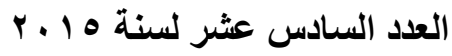
مجلة البحث العلمى فى التربية

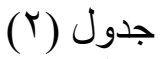

مقياس الفاعلية الأكاديمية و أرقام عبار ات كل مكون كما وردت في الصورة المبات النهائية للمقياس

\begin{tabular}{|c|c|c|}
\hline المجموع & أرقام المفردات التي يتضمنها كل مكون & مكونات المقياس \\
\hline 11 & $\left.r q_{-} r V_{-} r r_{-} r q_{-} r \theta_{-} r\right)_{-}\left|V_{-}\right| r_{-} q_{-} \theta_{-} \mid$ & دافعية الإنجاز \\
\hline 9 & $\left.\left.r \varepsilon_{-} r_{-} Y_{-} T_{-} Y_{-} \mid \Lambda_{-}\right) \varepsilon_{-}\right) \cdot-I_{-} r$ & التعاون الدراسي \\
\hline 9 & 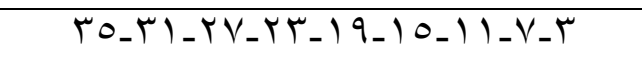 & إدارة وتتظيم الوقت \\
\hline 11 & 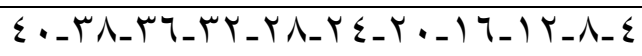 & مواجهة الضغوط الأكاديمية \\
\hline
\end{tabular}

Vاحساب المرغوبية الأجتماعية :رُوعي في الصورة الصوبه النهائية للمقياس تحقيق متطلبات خاصية

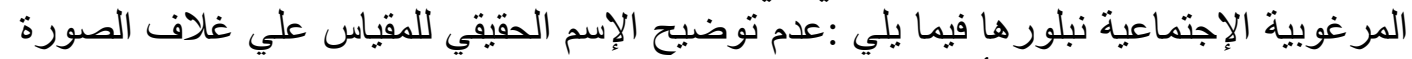

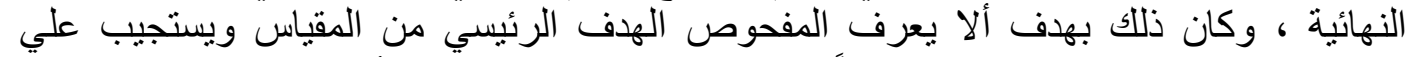

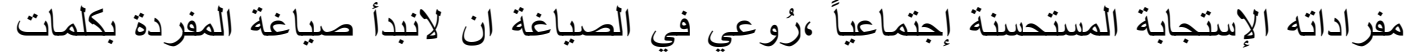

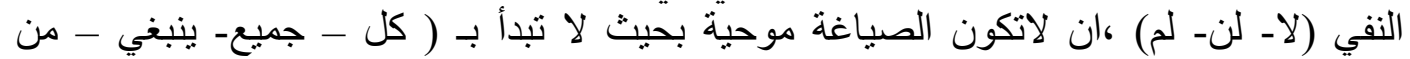

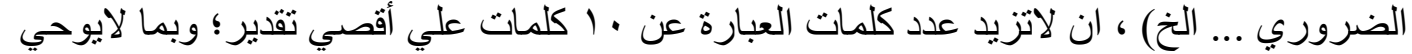

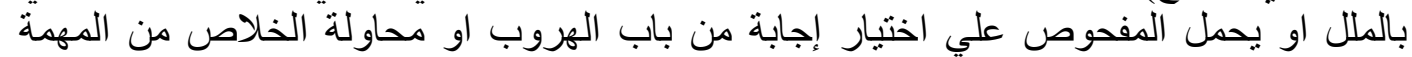

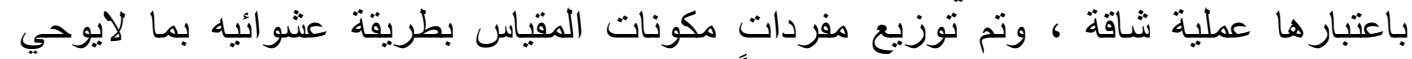
للمفحوصنين اختيار الاجابة المستحسنة إجتماعياً .

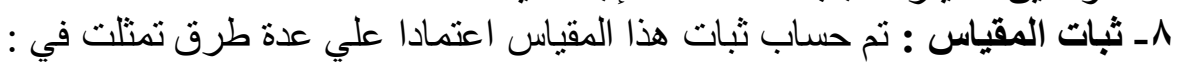

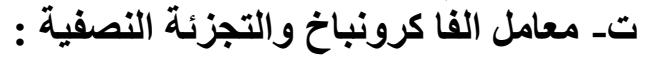
جدول ( ب) قيمة "ر" لحساب ثبات المقياس ومكوناته بطريقتي الفاكرونباخ والتجزئة النصفية

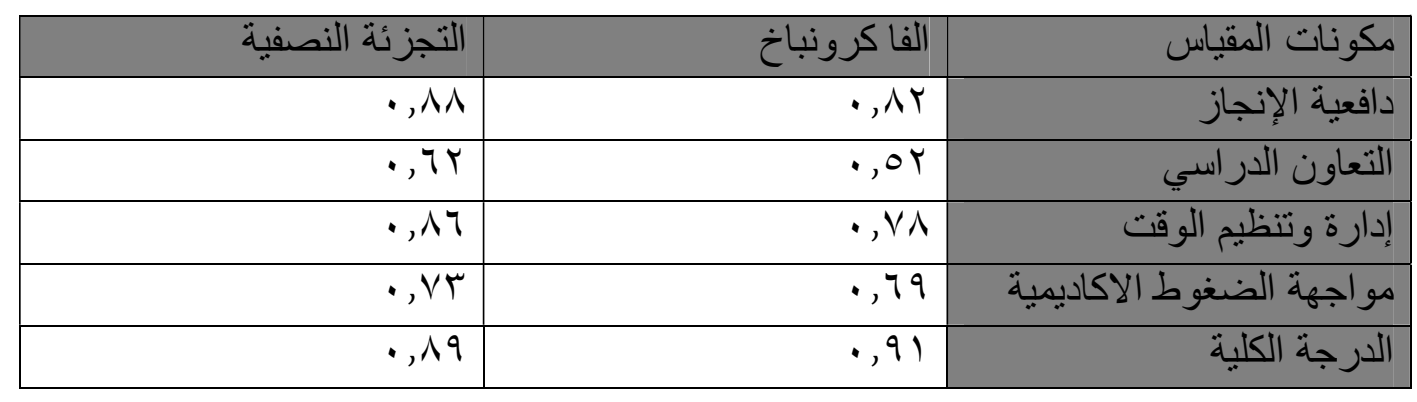

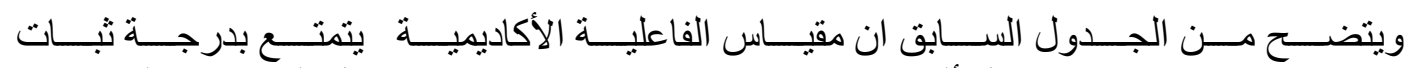

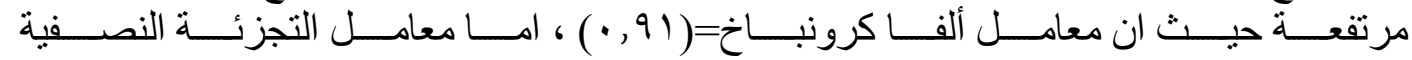

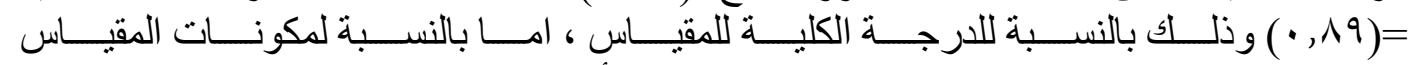

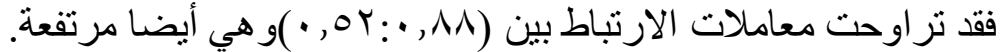

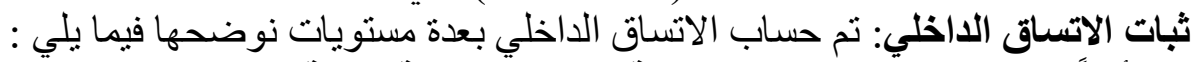

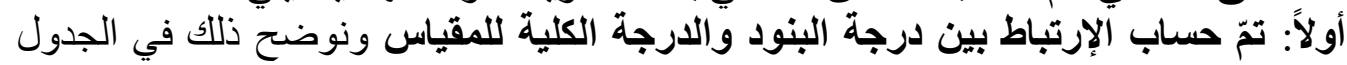


جدول ( ) ( )

قيم معاملات الارتباط بين مكونات الفاعلية والدرجة الكلية لحساب الثبات بطريقة الاتساق الداخلي

\begin{tabular}{|c|c|c|c|c|c|}
\hline قيمة (ر) & رقم البند & قيمة (ر) & رقم البند & قيمة (ر) & رقم البند \\
\hline ,,$\leqslant \leqslant * *$ & $r q$ & -,$\leqslant 1 * *$ & 10 & -,$r \nmid * *$ & 1 \\
\hline., $07 * *$ & r. &., $01 * *$ & 17 & - Tо** & $r$ \\
\hline$\cdot, \leqslant \vee * *$ & M & •, గо** & IV & - , $\leqslant \vee * *$ & r \\
\hline - Y૦*** & rr & ,,$\leqslant, * *$ & 11 & י, ז** & $\varepsilon$ \\
\hline -,$r \leqslant * *$ & سז & -, үq** & 19 & - , $\leqslant 0 * *$ & 0 \\
\hline י זּ** & $T \varepsilon$ & $1,01 * *$ & $r$. & $\cdot, 0, * *$ & 7 \\
\hline -,$\leqslant \leqslant * *$ & ro & -,$\leqslant 0 * *$ & YI & -,$\Gamma \leqslant * *$ & V \\
\hline -, $0 \leqslant * *$ & דו & - , $\leqslant 0 * *$ & Yr & - TV** & $\Lambda$ \\
\hline -,$\wedge * *$ & TV & -,$r \wedge * *$ & rT & -,$\leqslant\rceil * *$ & 9 \\
\hline - $\uparrow 9 * *$ & rᄉ &., $01 * *$ & TE & ., OY** & 1. \\
\hline - , $\leqslant\} * *$ & rq & ,,$\leqslant 9 * *$ & ro &., $00 * *$ & 11 \\
\hline $1,01 * *$ & $\varepsilon$. & • r & rt & -, rq** & $1 \%$ \\
\hline & & -,$\leqslant 9 * *$ & TV & - , $\leqslant$ ए** & r \\
\hline & & - , $\leqslant \nvdash * *$ & rᄉ & -,$\leqslant 0 * *$ & $1 \varepsilon$ \\
\hline
\end{tabular}

ثانياً : حساب الإتساق الداخلي بين درجة البند والارجة الكلية للمكون ، ونوضح ذلك في الجدول

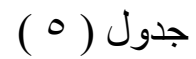

قيم (ر) بين درجة البند ودرجة المكون الفرعي الذي ينتمي إليه في مقياس الفاعلية الأكاديمية

\begin{tabular}{|c|c|c|c|c|c|c|c|}
\hline \multicolumn{2}{|c|}{ مواجهة الضغوط الأكاديمية } & \multicolumn{2}{|c|}{ إدارة وتشظيم الوقت } & \multicolumn{2}{|c|}{ التعاون الاراسي } & \multicolumn{2}{|c|}{ دافعية الإنجاز } \\
\hline قيمة (ر) & رقم البند & قيمة (ر) & رقم البند & قيمة (ر) & رقم البند & قيمة (ر) & رقم البند \\
\hline - , $\Gamma \vee * *$ & $\varepsilon$ & • ז־** & $r$ & $1,0, * *$ & $r$ & •,$\Gamma \leqslant * *$ & 1 \\
\hline., $01 * *$ & $\Lambda$ & . $\leqslant 0 * *$ & $V$ & • rı** & 7 &., $00 * *$ & 0 \\
\hline$\cdot, \leqslant 0 *$ & IT &., $01 * *$ & 11 & -,$\leqslant 7 * *$ & 1. & $\cdot, \leqslant 9 *$ & 9 \\
\hline •, & 17 & •, $\curlyvee * * *$ & 10 & ., qq** & $1 \leqslant$ &., $07 * *$ & $1 \pi$ \\
\hline ., १** & $r$. & , $0, * *$ & 19 & • ו & 11 & . ro** & 18 \\
\hline •,$\Gamma \vee * *$ & $r \varepsilon$ & .,$r \leqslant * *$ & $r T$ & . , $\leqslant 7 * *$ & rY & ., rq** & $Y_{1}$ \\
\hline •,$\leq 1 * *$ & $r \wedge$ & •,$\Gamma \leqslant * *$ & TV & -,$\leqslant 0 * *$ & $r 7$ & • , r०** & ro \\
\hline -, rq** & r & - , $\leqslant \nmid * *$ & M & .,$\leqslant\rceil * *$ & r. & •,$\Gamma \leqslant * *$ & rq \\
\hline -,$\leqslant\rceil * *$ & ru & $\cdot, \Gamma \wedge * *$ & ro & • r TV** & T\& & .,$\leqslant \leqslant * *$ & Tr \\
\hline$\cdot, r q *$ & $\Gamma \wedge$ & & & & &., $01 * *$ & $r V$ \\
\hline ·, $\leqslant 9 * *$ & $\varepsilon$. & & & & & $\cdot, \Pi \wedge * *$ & rq \\
\hline
\end{tabular}

9 صدق المقياس: تم الاعتماد علي عدة طرق ، نوضحها فيما يلي :

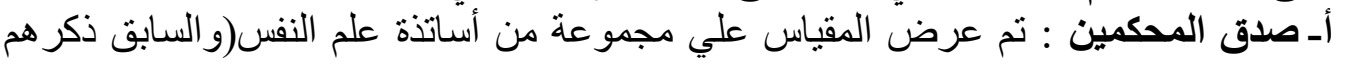
في الفقرة السابقة)، حيث طلب منهم تقدير صلاحية المقياس ، ومناسبة عباراته ، 
ووضوحها ، ومدي ارنباطها بالمكون، ونتيجة لذلك فقد تم استبعاد عبارات مثل (اهتم

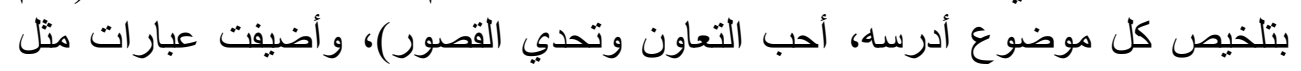
(اكثف جهدي للانتهاء من واجباتي ، اعجز عن التغلب علي مشاكل الوقت مع كثرة المهام

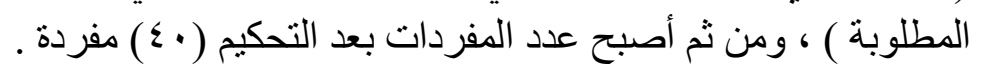

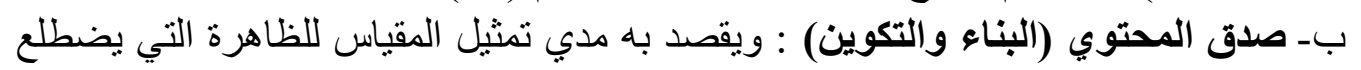

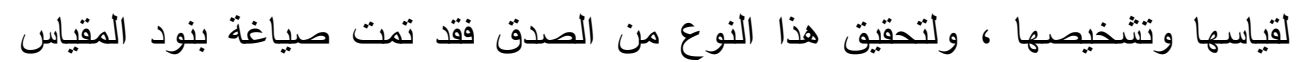

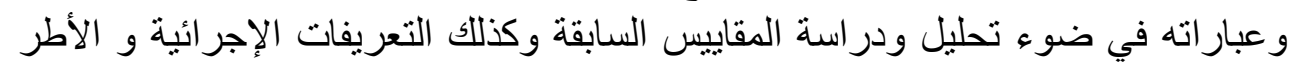

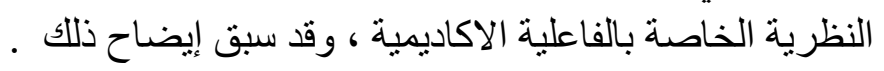

تتائج الدراسة : وتتضمن معالجة الفروض ومناقنة نتائجها في ضوء الدراسات السابقة

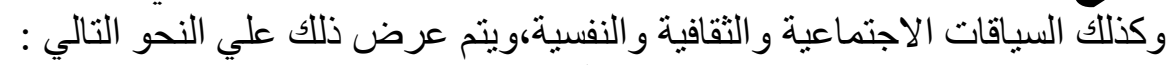

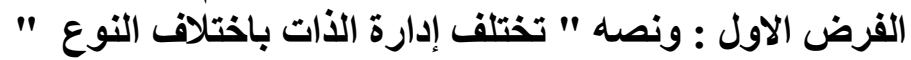

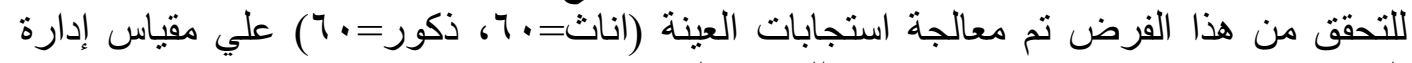

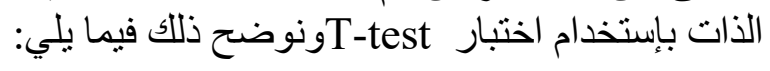

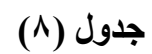

دلالة الفرق بين متوسطي الذكور والاناث في إدارة الذات

\begin{tabular}{|c|c|c|c|c|c|c|c|c|}
\hline التأثير & الدلالة & مستوي الدلاية & $\ddot{~}$ & الحرية & المتوسطين بين & المتوسط & العدد (ن) & العينة \\
\hline \multirow[t]{2}{*}{$1, \pi$} & \multirow[t]{2}{*}{ غير داله } & \multirow[t]{2}{*}{$\cdot, r \wedge$} & \multirow[t]{2}{*}{$r, 11$} & \multirow[t]{2}{*}{111} & \multirow[t]{2}{*}{$\vee, \wedge \bullet}$. & $19,0$. & 7. & الأكور \\
\hline & & & & & & $19,9 V$ & 7. & الانـاث \\
\hline
\end{tabular}

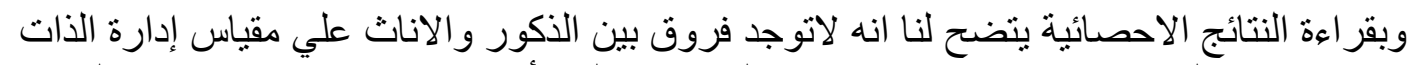

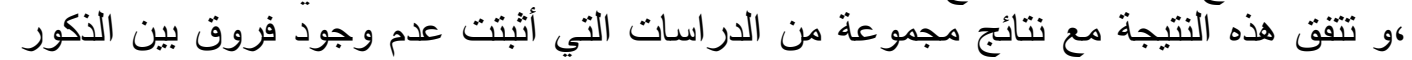
والاناث في إدارة الذات منها : در اسة Steven Charles,2001 حيث اجريت علئ علي عينة مكونه

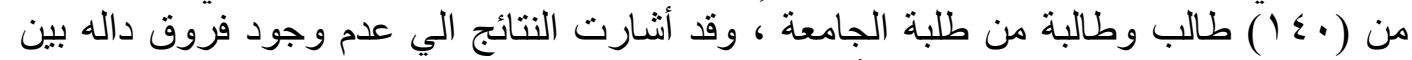

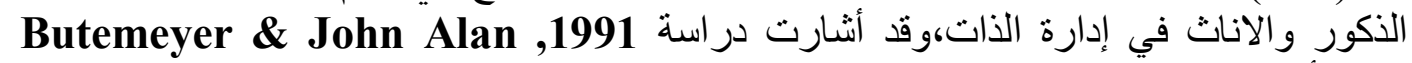

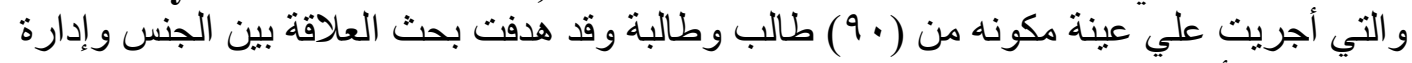

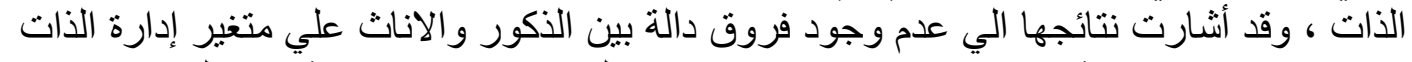

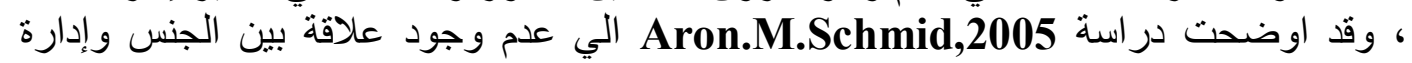
الذات ،وتتفق دراسة كلا من مع Purdie, N , Douglas, G.,1996 Zimmerman \& Martenz-Pons, 1990

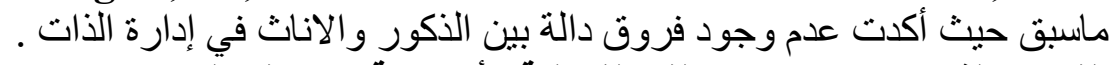

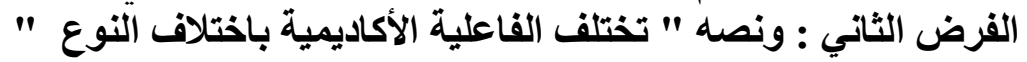

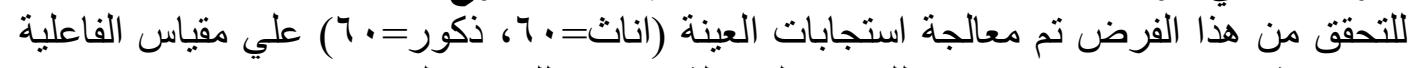
الاكاديمية بإستخدام اختبار T-test للعينات المستقلة نوضح فئح ذلك فيما يلي: 


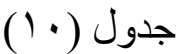

قيمة (ت) لالالة الفرق بين متوسطي الذكور والاناث علي مقياس الفاعلية الأكاديمية

\begin{tabular}{|c|c|c|c|c|c|c|c|}
\hline حجم التأثير & الالالة & مستوي & ت & الحرية & الفرق بين & المتوسط & العينة \\
\hline \multirow{2}{*}{ كبيز جدا 1 كب } & \multirow[t]{2}{*}{ غير داله } & \multirow[t]{2}{*}{$\cdot, \mu V$} & \multirow[t]{2}{*}{$\cdot, Y Y$} & \multirow[t]{2}{*}{111} & \multirow[t]{2}{*}{$\cdot, \mu$} & $1 \cdots, 70$ & الأكور \\
\hline & & & & & & $1 \ldots, 90$ & الاناث \\
\hline
\end{tabular}

وبقر اءة النتائج الاحصائية يتضح لنا انه لاتوجد فروق بين الذكور والاناث علي مقياس الفاعلية

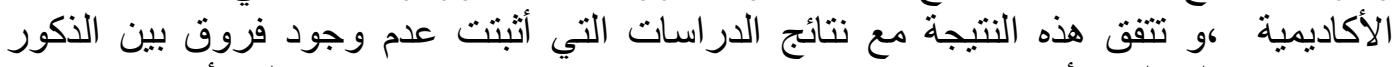

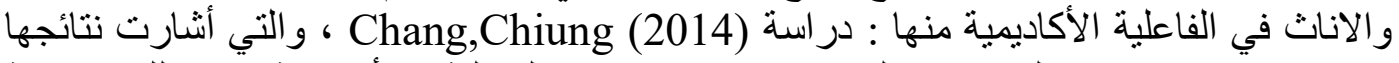

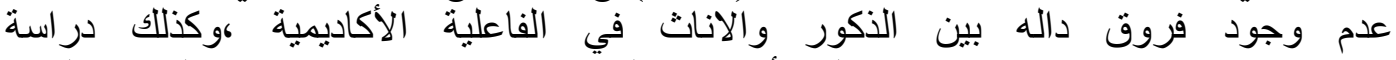

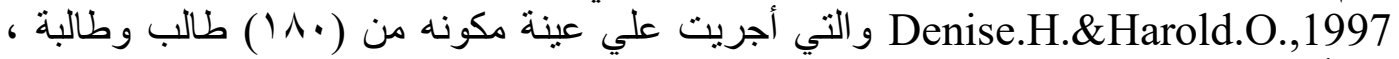

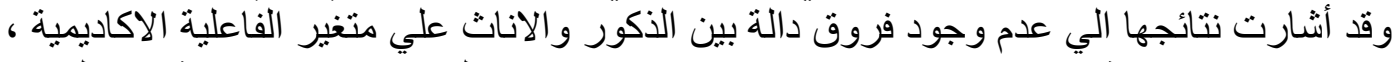

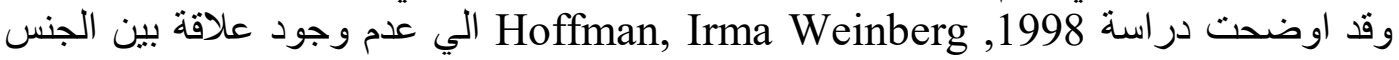

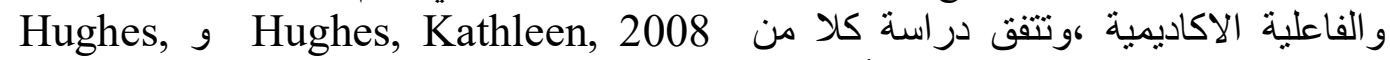
Kathleen,2008 ماسبق حيث أكدت عدم وجود فروق دالة بين الذكور و الاناث في الفاعلية الاكاديمية . و انطلاقا مما قدمته البحوث والاثة الدراسات السابقة نؤكد علي عدم وجود فروق جوهرية هين بين الذكور

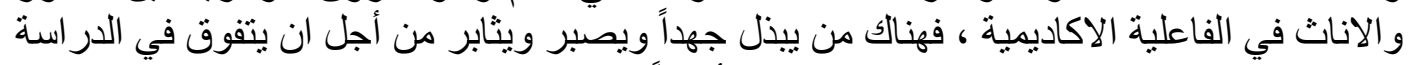

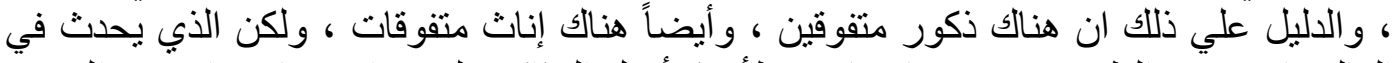

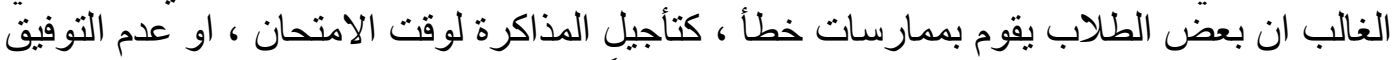

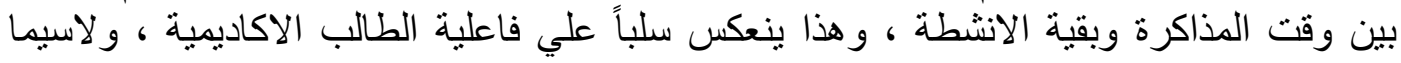

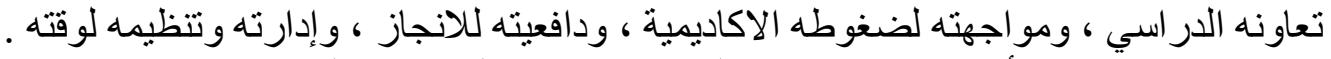

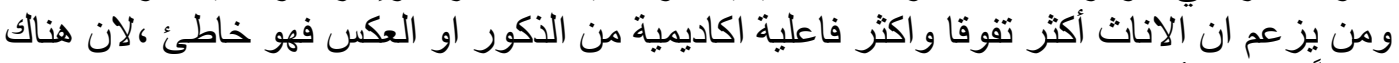

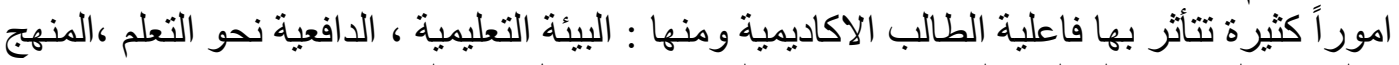

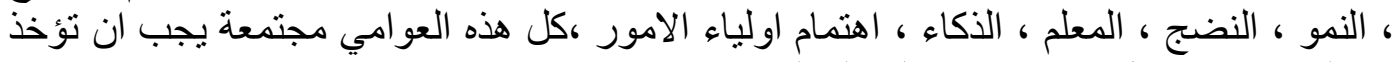

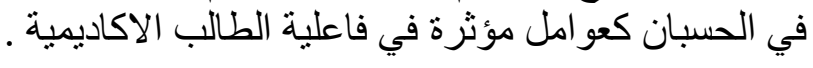

الفرض الثالث ونصه " يمكن التنبؤ بإدارة الذات من خلال الفاعلية الاكاديمية لدي طلاب الجامعة وللتحقق من صحة هذا الفرض تمت معالجة استجابات عينة الدر اسة من طلاب الجامعة (ن= ـ 10 )

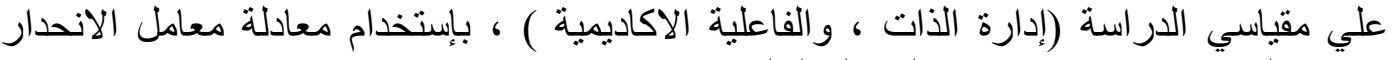

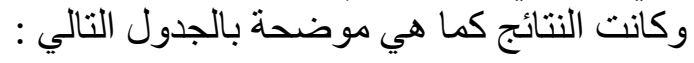




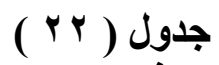

قيمة (ت) للتنبؤ بإدارة الذات من خلال الفاعلية الأكاديمية

\begin{tabular}{|c|c|c|c|c|c|}
\hline الالالة & قيمة(ت) & قيمة بيتا & المعياري & معامل B & القيم الاحصائية \\
\hline$\cdot, \ldots$ & $1 \cdot, r$ & & $\varepsilon, \leqslant 0$ & $\{0, \varepsilon \leqslant$ & الثابت \\
\hline$\cdot, \ldots$ & $9,0 Y$ & $\cdot, 7)$ &., .0 & $\cdot, \leqslant V$ & إدارة الأاداتمبة الفاعلية \\
\hline
\end{tabular}

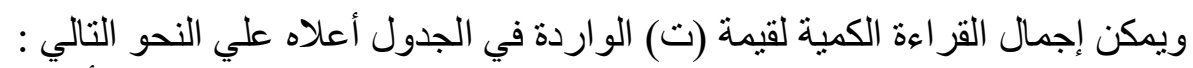

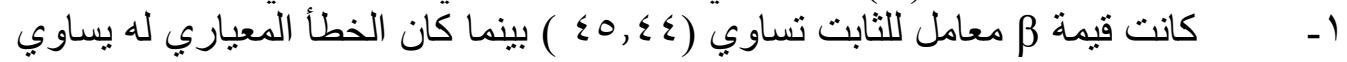
$(\varepsilon, \leqslant 0)$

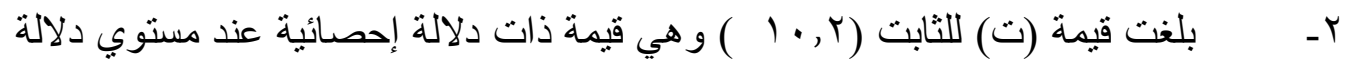
$(\cdot, \cdots)$

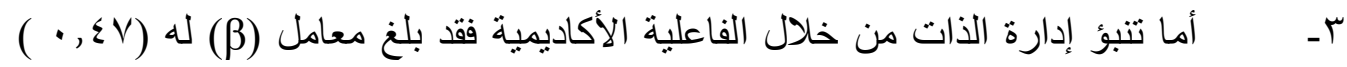

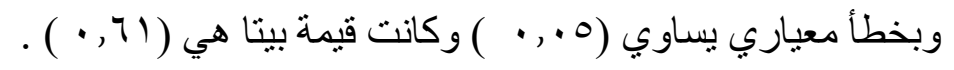

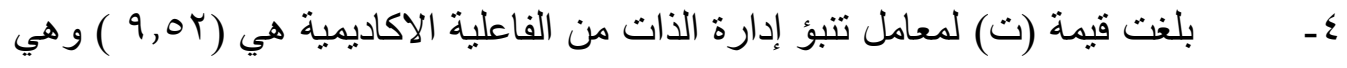

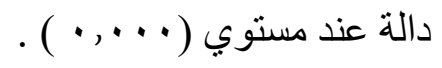

المناقثة والتفسير : يلاحظ ان أغلب الدراسات المعنية بهذين المتغيرين أكدت ان العلاقة بينهما

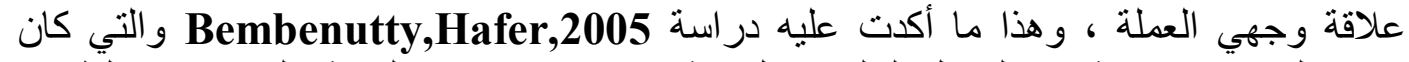

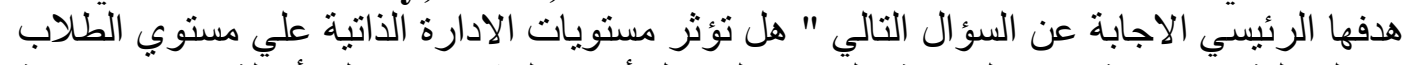

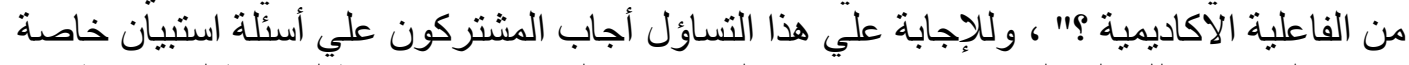

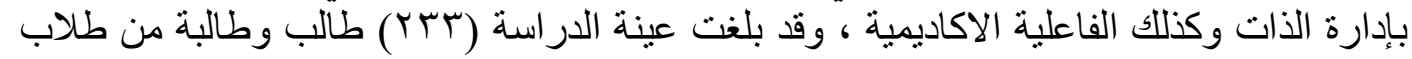

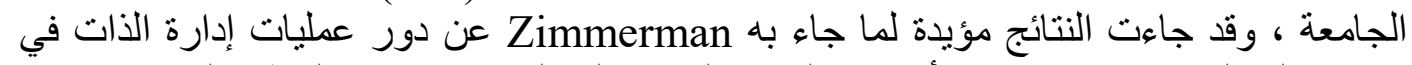

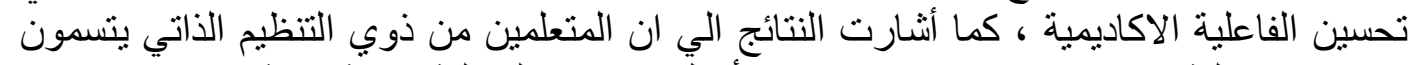

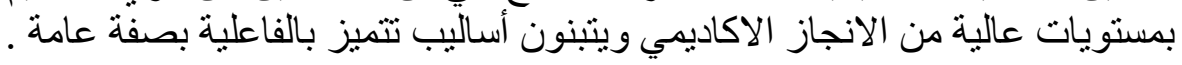

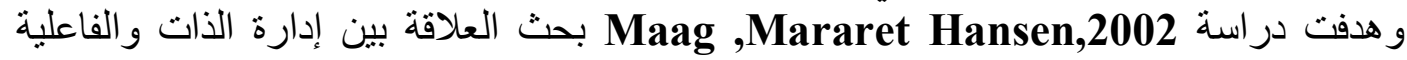

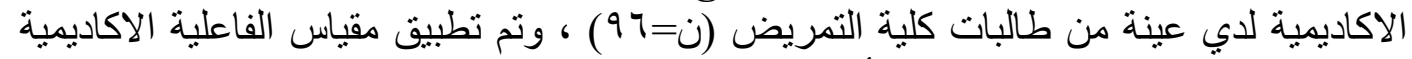

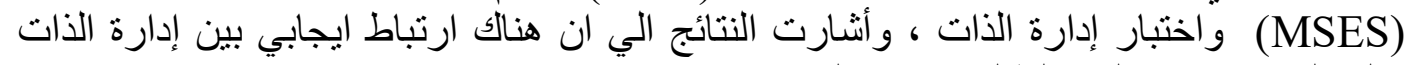

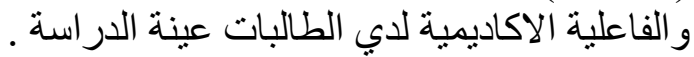
و هذا ما أكدت عليه أيضا دراسة Zook,Catherine Elizabeth,2000 حيث هدفت الإست إختبار

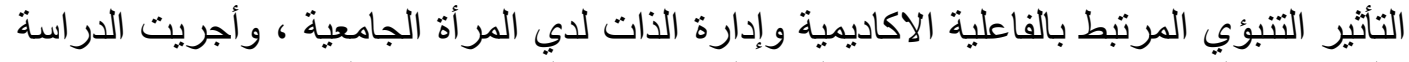

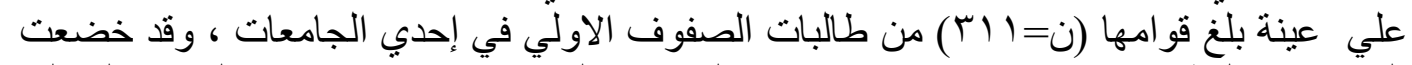

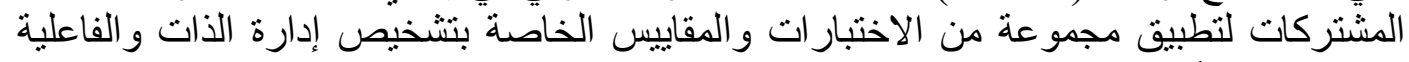

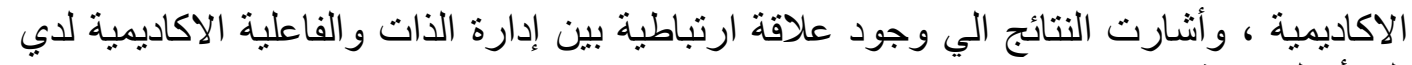

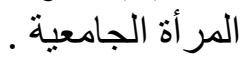

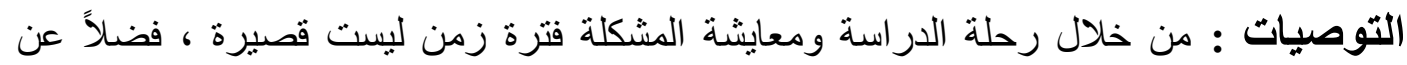

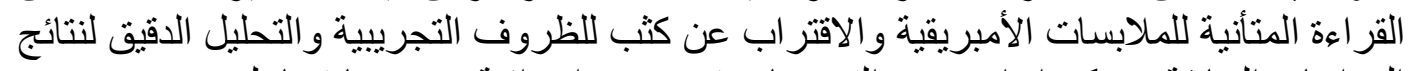

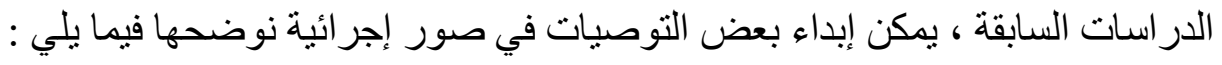




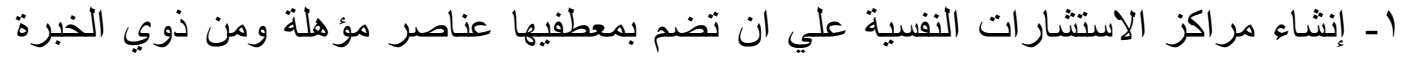

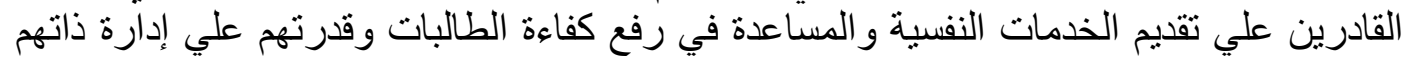

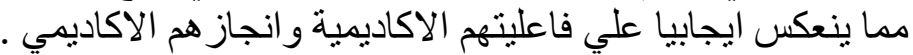

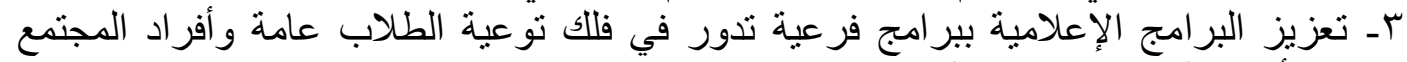

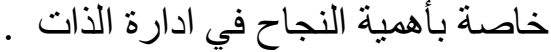
ع ـ عقد دور ات تدريبية تو عوية بعلاقة النة الدات ادارة الذات بالفاعلية الاكاديمية .

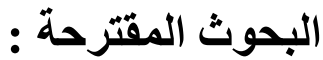

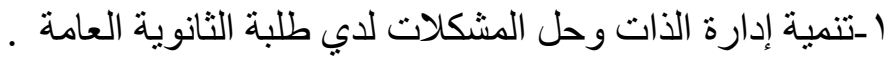

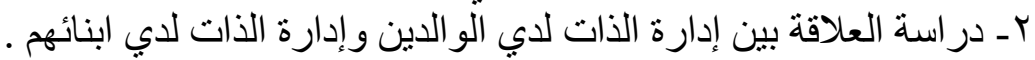

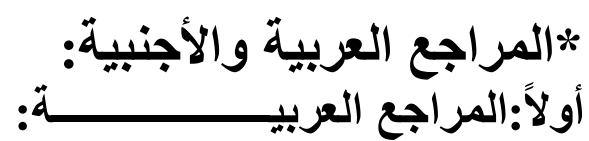

ا ـ ايمن غريب قطب (997 (9 ) ) : الكفاعة والفعالية والنمو النفسي للمراهق ، مجلة علم النفس ،

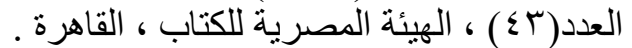

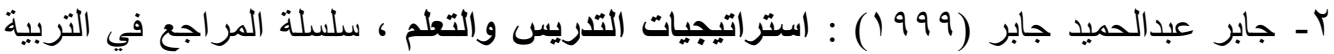

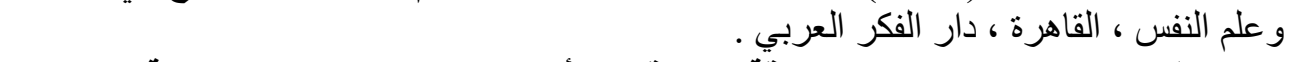

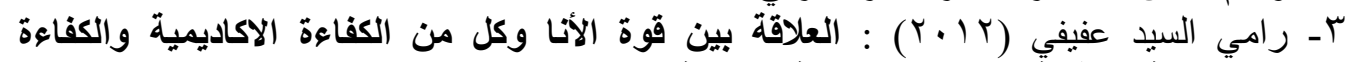

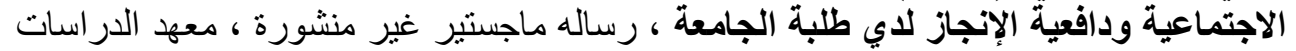

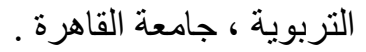

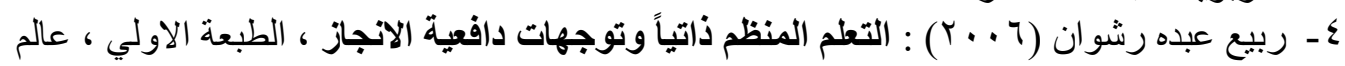

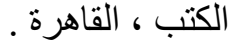

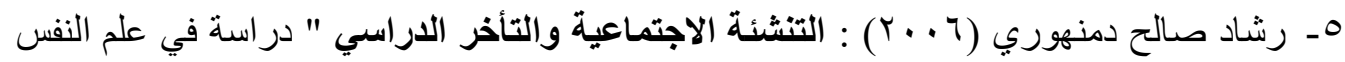

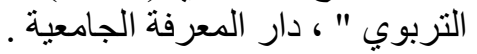

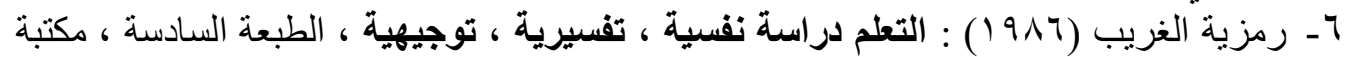

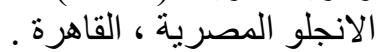

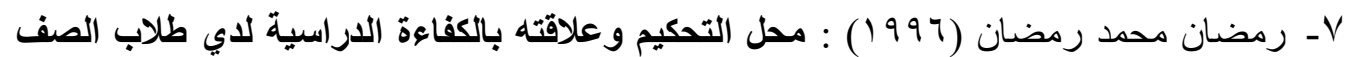

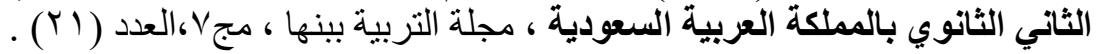

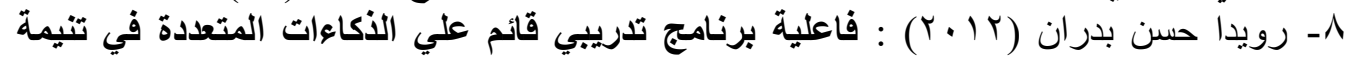

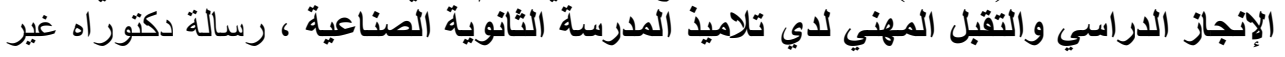

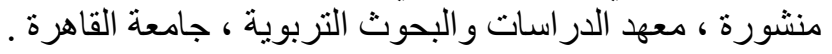

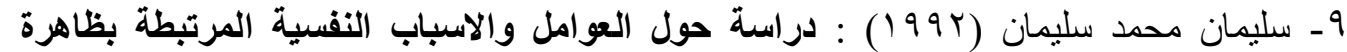

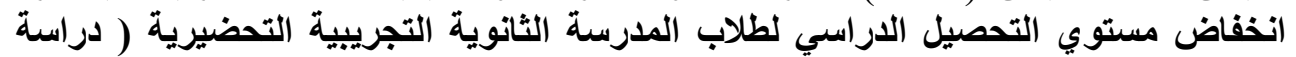

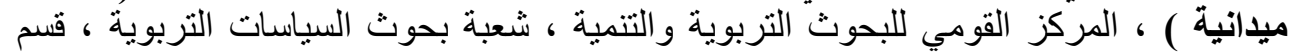

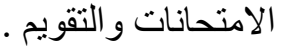

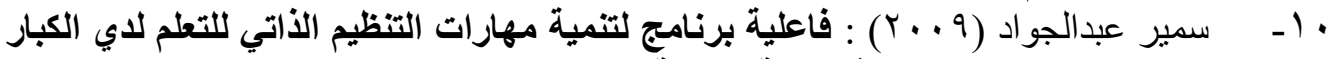

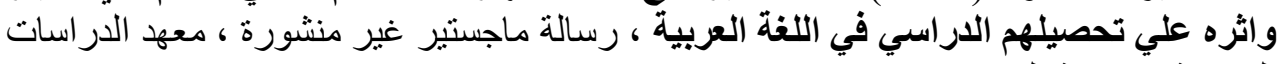

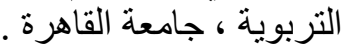

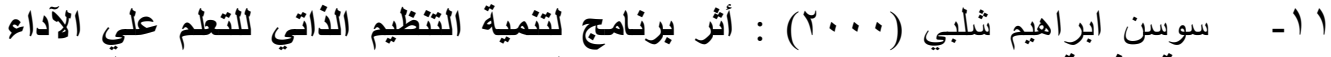

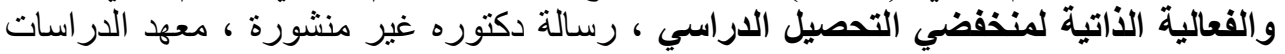

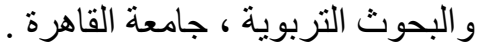

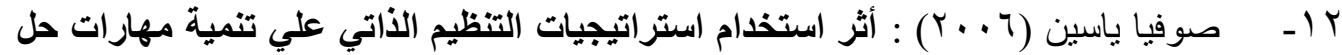

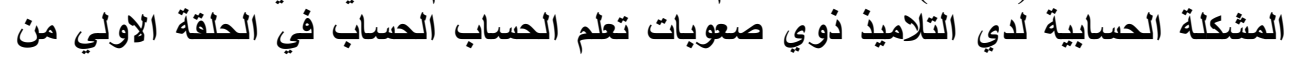




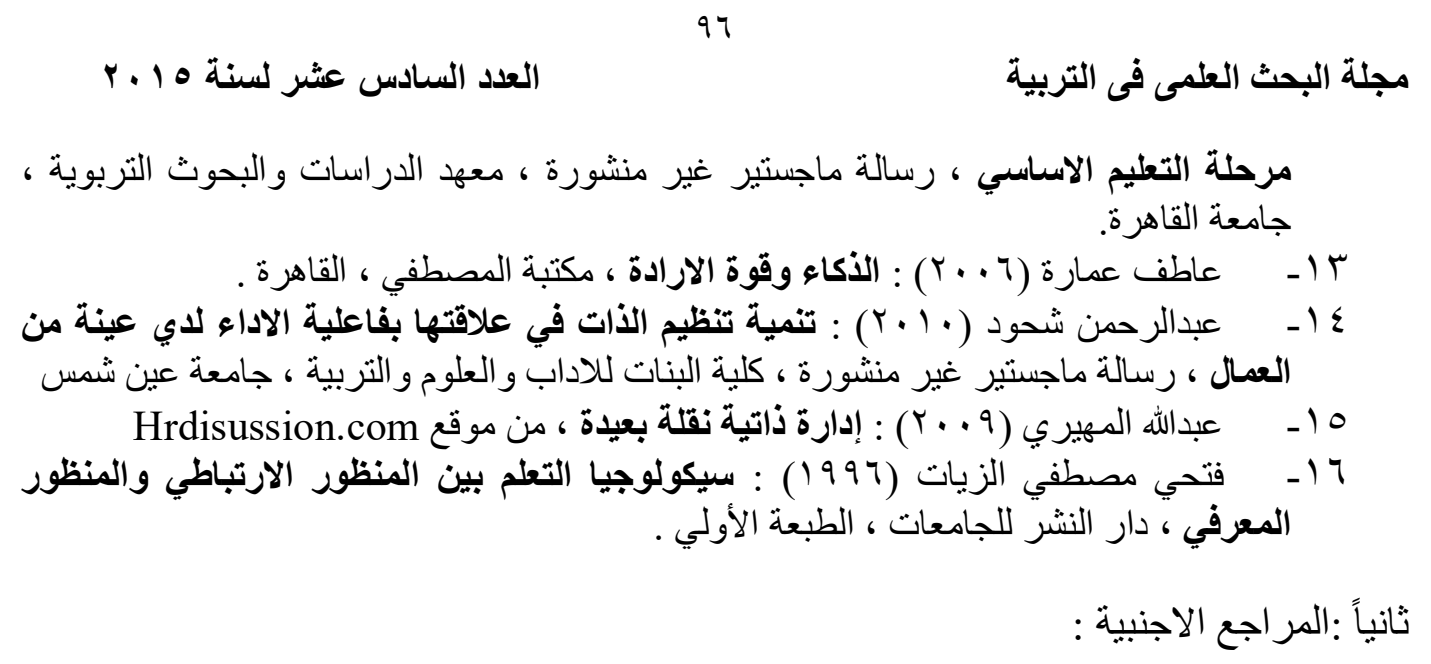

1- Aron ,M,Schmidt(2005).Self regulation in concuwent maltipl context :The role of discrepancies superordinate goal freming and individual differences an dynamic goal prioritization, ph.D.Michigan, university.

2- Brighamt,T,(1982): Self management a radical behavioral prespective in karoly ,p8. NewYork press.

3- Butemeyer\&John,A(1991) . The effects of goal type and ability on self regulation in simple and complex tasks .ph,D, Texas university,p122.

4- Denise ,H\&Harlod,O(1997): The role of parental expectation effort and self efficacy in the achievement of low and high school student in Taiwan,papae presented at the annual meeting of American educational research association .

5- Denise T.D.DE Ridder \& John B.F (2006) : Self-Regulation in Health Behavior ,West Sessex po19 8sq, England .

6- Diperna,James C,\&Elliott,Stephev,N(1999).Development and validation of the academic competence evaluation scales, journal of psychoeducational assessment ,vol(17),no3.

7- Dulewicz,V\&Higgs,M(1999):Emotional intelligence questionnaire compelemce ,vol6,no(1),pp1-10.

8- Epstein ,S,(1998).Constructive Thinking :The key to emotional intelligence ,West Port,CT,USA: Greenwood publishing group incorporated.

9- Fan,Fang,etal(2006). Relationship between college student's internet overuse tendency and their academic achievement, mental problems and family function.

10-Jennifer ,Suzanne, Beer (2002) . Self-Regulation of social behavioral ,ph.D,California ,University .

11-Kanfer .F.H\&Karoly.P(1972) : Self-Controle : Abehavioristic excusion into the lion ,s den Behavior therapy 2 pp378-416.

12-Lin ,M(1997) .Self Regulated learning and science achievement in A community college ,EdD, university of southern California ,Educational psychology ,vol 58,Diss,Abs,pp1558.

13-Norris ,Tina L(2010).Adolescents academic achievement, bullying behavior and the frequency of internet use .

14-Odaci,Hatice(2011).Academic self efficacy and academic procrastination as predictors of problematic internet use in university students .

15-Purdi,N\&Hattic,J(1996). Cultural differences in the Use of strategies for Seif regulated learning, American Educational Resea rchjournal ,33. 


$$
\text { مجلة البحث العلمى فى التربية }
$$

16-Robert Cobb ,Jr (2003) : The relation between self-regulated learning behaviors and academic performance in web basurses, ph.D. Virginia polytechnic institute and state university.

17-Stanlly Morries Gully (1997) : The imfluences of self-regulatory process on learning and performance in ateam treaning context vadami ,ph,D,Michhgan ,university.

18-Steven,Charles,Martino(2001): Dynamic self complexity reorganization of self knowledge as a means of goal directed self regulation ,ph.D Minnesota university. 
العدد السادس عشر لسنة ه 1 ـ مجلة البحث العلمى فى التربية 